
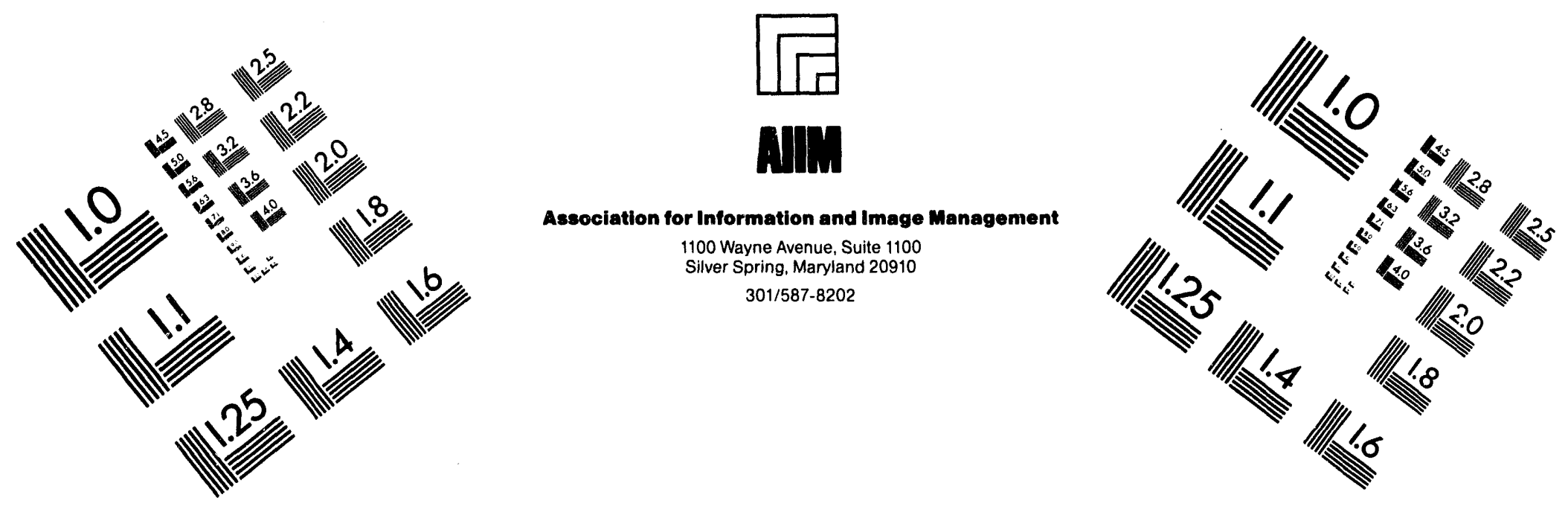

\title{
Centimeter
}

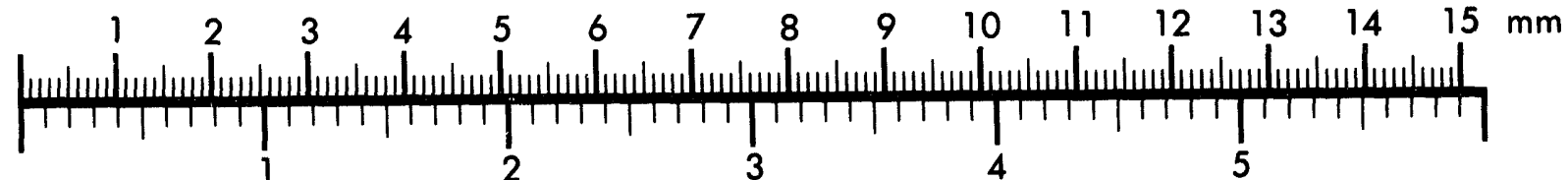
Inches
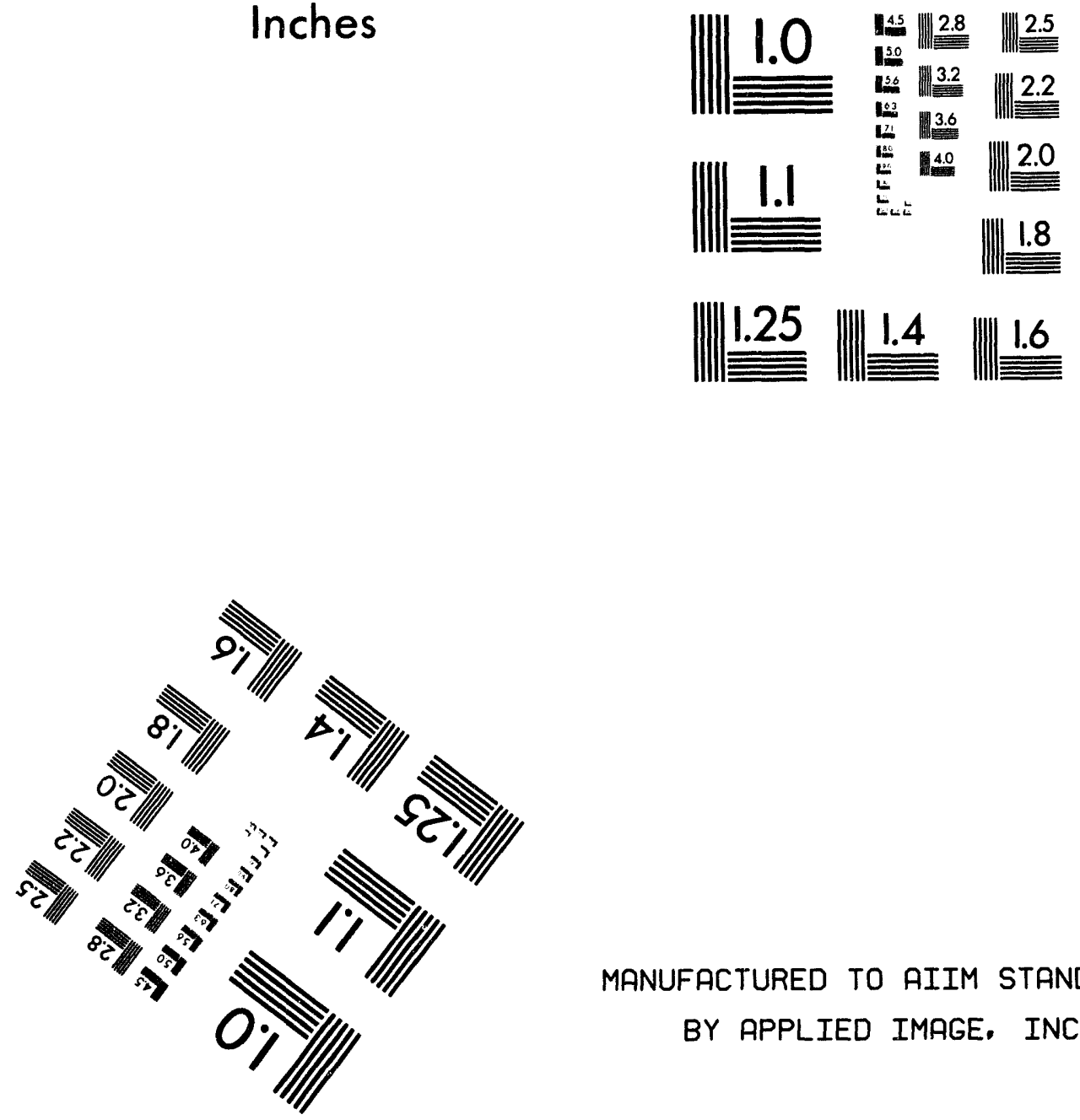

MANUFACTURED TO AIIM STANDARDS

BY APPLIED IMAGE, INC.

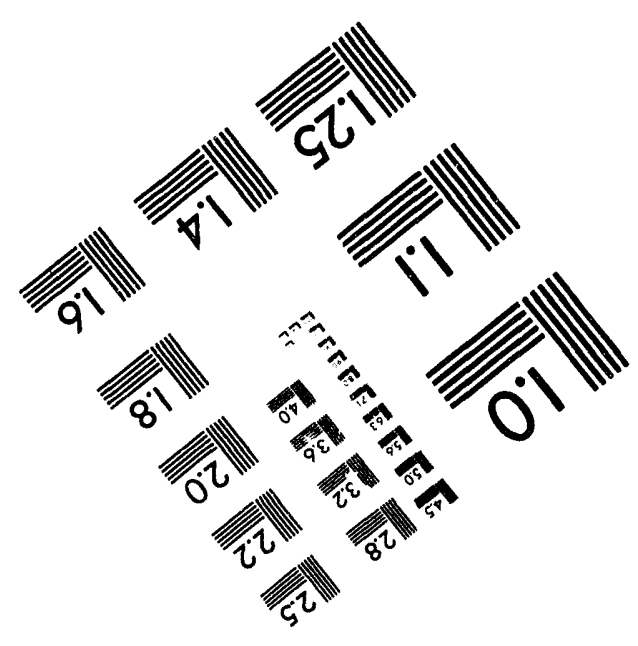



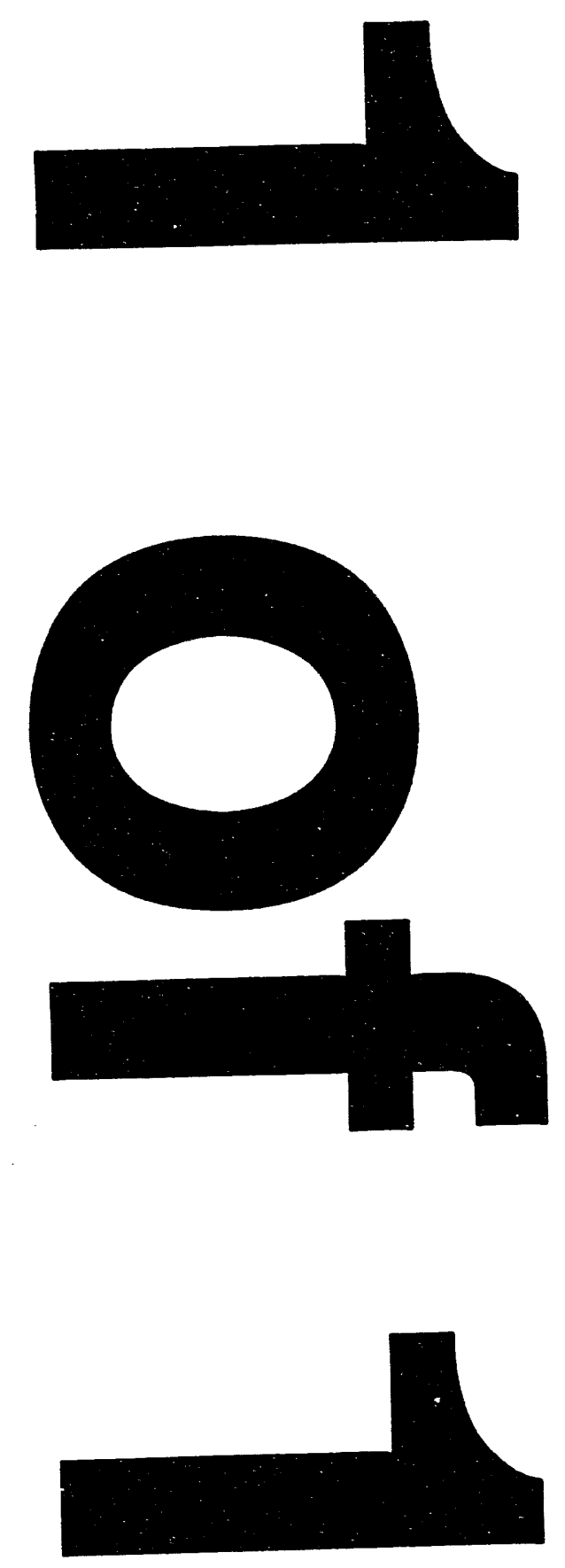


\section{PROGRIESS REPOFI}

The publiabed work in the accompanying references details much of the work in our List of Accomplishments and should be selfexplanatory. Here we describe results which have not yet been publiahed.

\section{Puritication of ${ }^{8} \mathrm{Cu}$}

${ }^{6} \mathrm{Cu}$ producad at the Brookhaven Linac lsotope Producer (BLP) is purified from zinctarget material and coproduced radiolsotopes of cobalt, chromium, nickel, and gallium by a multt-step extraction proceses. This procedus introduces applicable amounts of cold copper into the sample, lowering the specilic activity of the ${ }^{7} \mathrm{Cu}$. Because of this, the ${ }^{7} \mathrm{Cu}$ produced at BLP is not of high enough setvity for use in radioimmunotherapy procedures. It is our god to develop a procedure with which to purtly "Cu from the other radioisotopes produced, while at the same time minimize the amount of cold copper introduced into the system.

There are two difierent approsches that we devised for the purtication of ${ }^{\circ} \mathrm{Cu}$. They are an extrastion method similar to what ls used at Brookhaven already, and a copper affinity column.

\section{Extraction Muthod}

The advantages of ueing an extraction mothod are that it is easy to scale up to production size and that Brookthaven is already set up to perform extraction purtication.

Materials and methods. 6-(p-nitrobenzyl)-1, 4, 8, 10-tetraazacyclotetradecane-5, 7-dione (nitrobenzyl-dioxocyclam) was made by the procedure of Mol et al. (78). Molecular biology grade phenol was purchased trom Sigma Chemical Company. AG-1 x8 (100-200 mesh) anion exchange resin was purchased from Blo-flad. An econo column with dimensions $1 \times 14 \mathrm{~cm}$ was purchased form Blo-flad. The anion exchange resin was washed with four column volumes of $6 \mathrm{M} \mathrm{HCl}$ prior to loading on the sample. $\mathrm{HCl}$ solutions were prepared by bubbling $\mathrm{HCl}$ gas through water. Ultra-pure water (18 Ma cm-1) was used throughout. Sodium acetate solutions were prepared from sodium hydroxide and HPLC grade acetic acid. 2-aminoethoxyethanol, butyl lithium (1.6 M in THF, mydrazino, and dimethyl sulfoxide were purchased from Adrich Chemical Company. Chloromethylated polystyrene reain $(4.3 \mathrm{mmol} \mathrm{CV} / \mathrm{g})$ was purchased from Fuka Chemical Company. Thin-tayer chromatography (TLC) was run on plastic-backed silica gel plates (Neselgel 60 F254, EM Science). All other reagents were obtained from commercial sources and used without further purilication. A mock target soup (which contains $10^{3} \mathrm{M} \mathrm{Cr}, \mathrm{Ni}, \mathrm{Mn}, \mathrm{Co}$, and $10^{4}$ $M$ Ga in butfer) was made based on reported metal ion concentrations in the target material after irradiation. RLC plates containing radiolabeled material wore visualized with an AMBIS radioanalytle Imaging system. The copper content of both the dloxocyclam and the phenol were determined by Galbraith Laboratories inc. (Knoxville TN).

A general extraction procedure is as follows: Znc chloride was added to $1 \mathrm{~mL}$ of target soup to a final concentration of $1 \mathrm{M}$. To this solution was added pure ${ }^{67} \mathrm{Cu}$. Then nitrobenzyl-dloxocyclam was added to a final concentration of $25 \mathrm{mM}$. The $\mathrm{pH}$ was adjusted to 5.0 with saturated sodium acotate. The solution was incubated for 5-15 min at room temperature. Then $1 \mathrm{~mL}$ of phenol

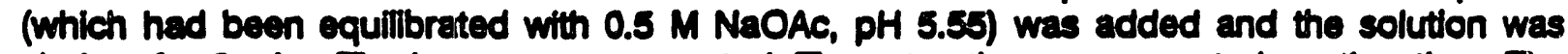
shaken for $2 \mathrm{~min}$. The layers were separated. The extraction was repeated another time. The phenol extracts were combined. The combined phenol extracts were extracted with $0.5 \mathrm{~mL}$ of 6 $\mathrm{M} \mathrm{HCl}$ by shaking for $2 \mathrm{~min}$. The loyers were separated and the phenol solution was extracted again with $0.5 \mathrm{~mL}$ of $\mathrm{HCl}$. The $\mathrm{HCl}$ oxtrects were combined and losded on a AG 1-x8 column (1 on $\times 15 \mathrm{~cm})$. The column was eluted first with.6 $\mathrm{M} \mathrm{HCl}$, then with $1 \mathrm{M} \mathrm{HCl}$. Fractions were

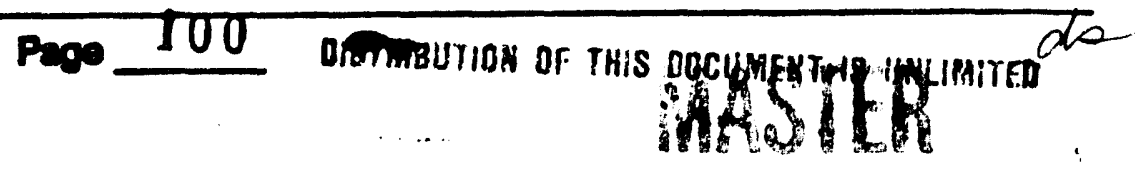


collected and messured on a gamma counter. The fractions with the most radioactivity were dried. Ttrations were done using nitrobenzyl-TETA, and the results wore compared to those of ${ }^{67} \mathrm{Cu}$ which hadn't been treated by this purfication procedure.

Results and diecussion. The initial extractions were done with target soup made up in $0.1 \mathrm{M}$ $\mathrm{NH}_{4} \mathrm{OAC}$. In these extractions, about $95 \%$ of the copper was taken up into the phenol solution. Aleo, the copper is removed from the phenol layer almost quantitatively, with an overall yield of 91\% after the $\mathrm{HCl}$ extractions. A study of incubation times showed that only $5 \mathrm{~min}$. was needed to achiove these results. To determine the uptake of other metals into the phenol layer, similar experiments were forformed, substtuting ${ }^{57} \mathrm{Co}$ and ${ }^{60} \mathrm{Ga}$ for ${ }^{\circ 7} \mathrm{Cu}$. Only $1 \%$ of ${ }^{7} \mathrm{Co}$ was taken up into the phenol layer, but $60-70 \%$ of ${ }^{6} \mathrm{Ga}$ was extracted into phenol.

Subettution of sodium citrate and ammonium citrate buffers for ammonium acotate reduced ${ }^{\infty} \mathrm{Ga}$ uptake to $1-5 \%$, but also reduced ${ }^{7} \mathrm{Cu}$ uptake to $75 \%$.

Finally, an oxtraction of target soup in $0.05 \mathrm{M}$ sodium acetate buffer was performed. In this extraction, the final concentration of nitrobenzyl-deoxycyclam was $20 \mathrm{mM}$. $5 \mathrm{M}$ sodium acetate was used to adjust the $\mathrm{pH}$ to 5.0. The solution was incubated $15 \mathrm{~min}$ before extraction in phenol. Uncer these conditions, uptake of ${ }^{\circ} \mathrm{Cu}$ into phenol was 93.67 and uptake of ${ }^{\circ} \mathrm{Ga}$ was only 21.5\%.

The extrection procedure above was performed ove the $\mathrm{pH}$ range 3.0 to 6.0 at $25^{\circ} \mathrm{C}$ and $37^{\circ} \mathrm{C}$. It was observed that optimum " $\mathrm{Cu}$ uptake is achieved at pH 5.0-5.5. No significant temperature. effects were observed.

One of the most important crtteria of the reagents used is that they are as free of copper as possible. The copper content of the phenol, dioxocyclam, and NaOAC should not exceed the low ppb range. The phenol used is molecular biology grade, and the nitrobenzyl-dioxocyclam has been recrystallized as the hydrochloride salt. Both of these compounds have been analyzed for copper content. The copper content of the nitrobenzyl-dioxocyclam and phenol were 120 and $17 \mathrm{ppb}$ respectively. Although dioxocyclam is relatively high in copper concentration, only small amounts are required for the extraction process. To purity $100 \mathrm{~g}$ of target material it would only take $4.5 \mathrm{~g}$ of dioxocyclam. Uaing this much dioxocyclam would introduce only $0.54 \mathrm{ug}$ of cold copper into the system. To pertorm the same extraction it would take $1 \mathrm{~L}$ of phenol to purify 100 $\mathrm{g}$ of target material. This amou it of phenol would introduce $17 \mathrm{ug}$ of cold copper into the system. Attempts to further purtly the phenol by equillbrating with buffer containing EDTA are being examined.

Copper aninity column. A one step puritication of ${ }^{87} \mathrm{Cu}$ from Zn target material on a sopper afinity column would be less vulnerable to the introduction of other metal impurittes such as "cold" copper than currently used multi-step extraction techniques.

The specificty of copper is provided by macrocyclic chelates attached to an inert solid-matrix support. The macrocyclic chelating agent TETA, for example, has demonstrated selective binding of copper in the presence of selected motal ion competftors, including zinc (79). In this experiment, the extent of copper binding by antibody-TETA,-DOTA,-NOTA, and EDTA immunoconjugates in the presence of swamping concentrations of calcium, magneslum, and zinc ion was examined. As seen in pand $A$ of Figure 2 below, only the antibody-TETA conjugate complexed only copper in the presence of up to $10^{4}$ equivalents of zinc, calcium, or magnesium. 
FIgure 2
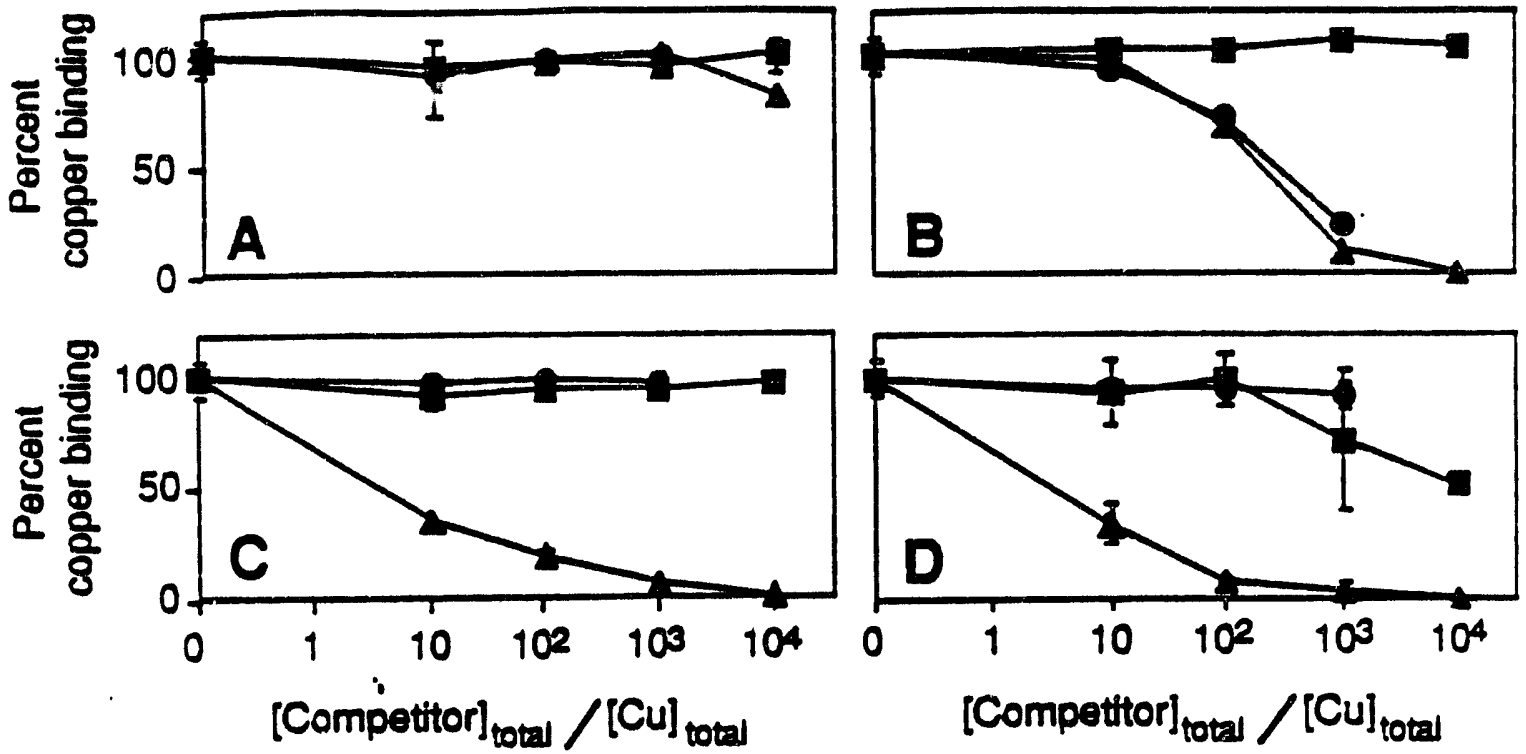

Measured efficiency of copper complexation by the antibody-TETA conjugate (A), the antibodyDOTA Conjugate (B), the antbody-NOTA conjugate (C), or the antibody-EDTA conjugate (D) in the presence of compettiors zine ( $)$, magnesium (). or calcium ( ). Error bars represent the range of values for duplicate experiments; where no error bars are visible, the range was smaller than the symbol.

The results of the selective-binding experiment were in good agreement with equilibrium calculations for proton and metal ion binding by unsubstituted chelators. The conditional stability constants in the following graph (Figure 3) show that the 14-membered macrocycte in TETA has considerable preference $\left(=10^{\circ}\right.$ ) for binding copper instead of zinc or other common metal ions. Since zinc is the accelerator target used to produce ${ }^{\circ} \mathrm{Cu}$, molecules with copper selectiviny could be the basis for a new one-step procedure for isolating ${ }^{7} \mathrm{Cu}$ from excess zinc.

logks(cond) of Cu, Zn, Ca \& Mg-TETA pH in $\mathrm{B2O}$

F1gure 3

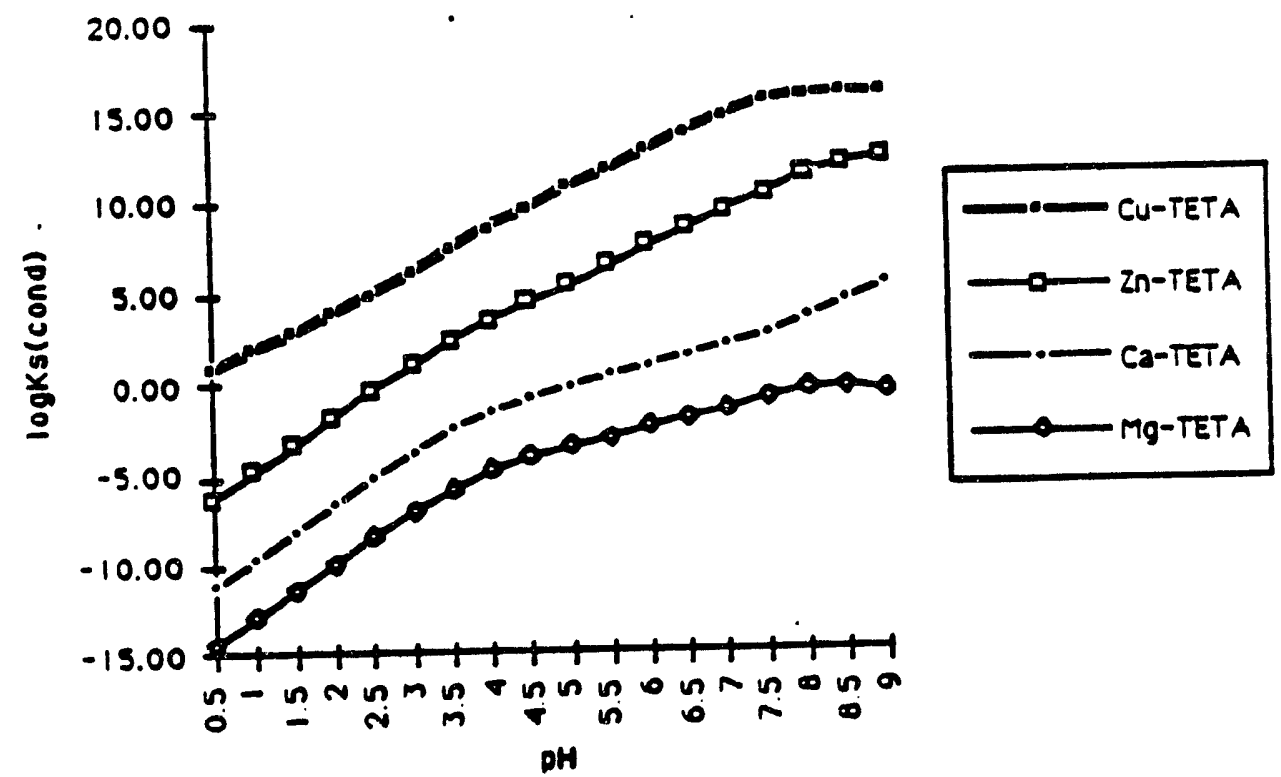

Pege In2 
Other macrocyclic ligands with selectivity for copper are under investigation for use in a copper affinity column. A solution of sample material containing 1.0 molar $\mathrm{Zn}, 1$ nanomolar ${ }^{\circ 7} \mathrm{Cu}$, and various other trace metals in $0.1 \mathrm{M}$ sodium acetate, $\mathrm{pH} 6$, was loaded onto a prototype column using a tetramethyl cyclam ligand. Zn and the other metals were eluted off the column with 0.1 $M$ sodium acetate, pH 4.5, while the copper remained quantitattvely bound by the immobilized macrocycles in the matrix. copper was then removed by elution with $6 \mathrm{M} \mathrm{HCl}$ and the copper (II) chloride was collected tree of other motals. However, the strong acid caused some organic material to olute from the column as well. We are currently refining this technique, using a dioxocyclam ligand that releases copper more easily at mildly acid $\mathrm{pH}$, as described in the Dotailed Laboratory Methods section.

\section{Macrocycic Chelates for Targeted Therapy}

Bifunctional macrocyclic chelates have been developed to conjugate metals to antbodles (80-82), and motal chelated antibodles have been shown to have slower clearance from the tumor than iodinated antibodies (83-85). This provides a mochanism for increasing tumor radiation dose and the therapeutic index. ${ }^{7 \mathrm{Cu}}$, produced by the proton bombardment of zinc (86), is one of the most promising radiomotals for therapy. Because ${ }^{\circ 7} \mathrm{Cu}$ releases abundant beta particles with energies like those of ${ }^{131} \mathrm{I}$ and a moderate abundance of gamma emissions with energies, it is excellent both for imaging and therapy.

1,4,8,11-tetraazacyclototradecano-N, $N^{\prime}, N^{\prime \prime}, N^{\prime \prime \prime}$-totraacotic acid (TETA) was doveloped as a chelating agent for "Cu (84-87). Copper chelated TETA, conjugated to monoclonal antbodies, is very stable in human serum under physiological condlitons (88). Moreover, TETA exhibits extraordinary selectivity for copper in the presence of high concentrations of metal ion competitors, including zinc ion (79).

Conditions for ${ }^{\circ 7} \mathrm{Cu}$ radiolabeling of TETA immunoconjugates have been optimized, leading to rapid, quantitative complexation of metal binding sites (88), further contributing to high radioactive yield and to the routine production of ${ }^{87} \mathrm{Cu}$ radiolabeled immunoconjugates of therapeutic quality $(89,90)$. The pharmacokinetics and radiation dosimetry of ${ }^{\circ}$ Cu-BAT-Lym-1 were similar to those of ${ }^{131}$ H Lym-1 except that lymphomatous tumors received radiation doses several times greater than those from ${ }^{131}$-Lym-1 because of retention of the ${ }^{67} \mathrm{Cu}(84,90,91)$. The therapoutic potential of "Cu-BAT-Lym-1 has also been shown in patients (92).

Macrocycles for ${ }^{\circ} \mathrm{Cu}$ and ${ }^{\circ}$. The macrocyclic chelates TETA and DOTA were designed and produced specilically for copper and yttrium by Dr. Claude Meares and his students. Bromoacetamidobenzyt TETA (BAT) and DOTA (BAD) are conjugated via 2-iminothiolane (2rT) to Lym-1 to prepare the immunoconjugates 2rT-BAT-Lym-1 and 2rT-BAD-Lym-1 with preservation of immunoreactivity. These immunoconjugates have been shown to bind ${ }^{\circ 7} \mathrm{Cu}$ and ${ }^{8 \%}$ with extraordinary stability in physlologic milleu. The radiochemistry required for TETA and DOTA to conjugate ${ }^{\circ} \mathrm{Cu}$ or ${ }^{\circ} \mathrm{Y}$, respectively, to Lym-1 has been completed as have the procedures necessary to prepare sterile and pyrogen-free radiopharmaceuticals. Preclinical studles with "Cu-BAT-Lym-1 and "In "Y Y-BAD-Lym-1 were completed and lod to our active INDs for these radiopharmaceuticals. Murine studles have shown similar pharmacokinetics of ${ }^{111}$ /n and soy-2rT-BAD-Lym-1 in mice. In these studies, indium did not escape to the reticuloendothelial system nor yttrium to the skeleton. Blodistribution studies of ${ }^{87}$ CU-2rT-BAT-Lym-1 and SOY-2TT-BAD-Lym-1 in athymic mice bearing human Rajl Iymphoma showed that tumor retention of these agents was greater than that of iodinated Lym-1. Furthermore, there was no detectable accumulation of ${ }^{7} \mathrm{Cu}$ in the bone or marrow. 


\section{"Cu-2T-BAT-Lym-1 Phamacolinetica/Dosimetry Studies}

Pharmacokinotic/dosimotric studies with ${ }^{67}$ CU-2rT-BAT-Lym-1 (TETA) have been complotod in 12 patients (Tables 1 \& 2) with comparisons to the pharmacokinetics of ${ }^{131} \mathrm{H}-\mathrm{Lym}-1$ in 8 of these patients. The rolattve pharmacokinotica/dosimetry in these eight patients contirmed projections that ${ }^{\circ 7} \mathrm{Cu}$ is an exciting therapeutic as well as quantitative imaging radionuclidc. Quantititive imaging was superb because the photons of ${ }^{\circ} \mathrm{Cu}$ are similar to those of ${ }^{\circ i n}$ TC. Despite a lesser photon abundance, there were five times more useable photons for each $\mathrm{mCl}$ of ${ }^{7} \mathrm{Cu}$ when compared to ${ }^{131}$. SPECT for ${ }^{\circ} \mathrm{Cu}$ was also superior when compared to ${ }^{131}$ I SPECT images.

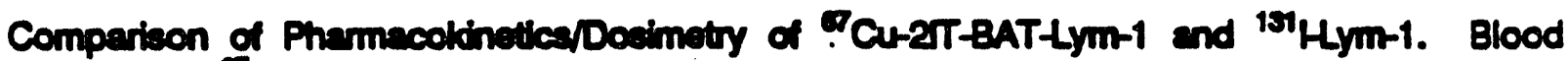
clearance of ${ }^{7} \mathrm{Cu}$ was slightly longer, urinary excretion less, and fecal excretion slightly greater than that of ${ }^{15 \%}$. Tumor uptake was equal or greater than ${ }^{131} \mathrm{H}-\mathrm{Lym}-1$, and tumor retention much more prolonged. This resulted in tumor radiation doses for ${ }^{\circ} \mathrm{CU}-\mathrm{BAT}-\mathrm{Lym}-1$ that were several times greater than those of ${ }^{131} /$ Lym $_{1} 1$ (Figure 4). Tumor regression occurred in three patients who received 5-10 mCl imaging doses. There was no evidence for accumulation of ${ }^{7} \mathrm{Cu}$ in the marrow in the absence of marrow lymphoma. Marrow radiation doses wore 1.5 times greater for ${ }^{6} \mathrm{Cu}-\mathrm{BAT}$-Lym-1 than ${ }^{131} \mathrm{H}$-ym-1 because of slower clearance from the pattent. Retention of ${ }^{67} \mathrm{Cu}$ Lym-1 in the llver was greater with corresponding greater radlation doses. None of these patients developed an ant-TETA antibody response. Five (42\%) of 12 patients given imaging doses had reactions to the antbody.

\section{FCu-BAT-LM-1 Patient Therapy Feasibirity Study}

Subsequenthy, three patients were treated with a total of 8 doses of ${ }^{\circ 7} \mathrm{CU}-\mathrm{BAT}-\mathrm{Lym}-1$. One patient who received 5 therapy doses had a complete response. One patient who recelved 1 therapy dose before HAMA occurred had a partial response and one patient progressed after 2 therapy doses. The major toxicity was hematologic. Two patients experienced a Grade 4 and one patient experienced a Grade 3 toxicity. The MTD for 2 doses of ${ }^{\circ}$ Cu-BAT-LYM-1 given 4 weeks apart was $60 \mathrm{mCl} \mathrm{m}^{2}$. Remarkably, this is what was anticipated when the relattve marrow radiation doses of ${ }^{\circ} \mathrm{Cu}$ and ${ }^{131} \mathrm{H} \mathrm{Lym}-1$ were considered, and adds validity to the relative radiation dose estimates. Because of the promising results in this DOE foasibility dosimetry and MTD study, the ${ }^{7} \mathrm{Cu}-\mathrm{BAT}$ Lym-1 phase 2 study will be initiated under $\mathrm{NCl}$ clinical tunding. Further basic questions relating to the molecular biological response of those patient tumors and the related tumor cell dosimetry will be pursued under this DOE funding.

\section{DISCLAIMER}

This report was prepared as an account of work sponsored by an agency of the United States Government. Neither the United States Government nor any agency thereof, nor any of their employees, makes any warranty, express or implied, or assumes any legal liability or responsibility for the accuracy, completeness, or usefulness of any information, apparatus, product, or process disclosed, or represents that its use would not infringe privately owned rights. Reference herein to any specific commercial product, process, or service by trade name, trademark, manufacturer, or otherwise does not necessarily constitute or imply its endorsement, recommendation, or favoring by the United States Government or any agency thereof. The views and opinions of authors expressed herein do not necessarily state or reflect those of the United States Government or any agency thereof.

\section{Pag 104}


TABLE 1 67CU-BAT-Lym-1 Phamacokinetics (TOP) and Dosinetry (BOTTOM)

\begin{tabular}{|c|c|c|c|c|c|c|}
\hline \multirow[b]{2}{*}{ Pesterk } & \multicolumn{3}{|c|}{${ }_{\text {(nir) }}^{\text {Bloed } T_{k}}$} & \multicolumn{3}{|c|}{$\begin{array}{c}\text { Whale Eady } T_{x} \\
\text { (dexp) }\end{array}$} \\
\hline & Apha & Ban & $\begin{array}{l}\text { Merrew From } \\
\text { Bloed fElphealed }\end{array}$ & Blolegend & Erecoutwo & $\begin{array}{l}\text { Marrow From } \\
\text { Whols Body }\end{array}$ \\
\hline 1 & a.1 & 4.8 & 2.01 & 302 & 24 & 0.18 \\
\hline 2 & 1.0 & $\operatorname{sen} 3$ & 0.33 & 60 & 1.8 & 0.14 \\
\hline 3 & 1.8 & 100.0 & 0.00 & 5 & 1.8 & 0.13 \\
\hline 4 & 1.1 & 220 & 0.10 & 192 & 21 & 0.14 \\
\hline 5 & 13 & 202 & 0.00 & 100 & 22 & Q.18 \\
\hline 8 & 1.8 & 40 & 0.07 & 7.4 & 12 & 0.13 \\
\hline 7 & 0.4 & 187 & 0.18 & 17.1 & 22 & Q.18 \\
\hline • & 23 & 328 & 0.18 & 10.0 & 21 & 0.14 \\
\hline 9 & 0.4 & 240 & 0.03 & 10.0 & 24 & Q.10 \\
\hline 10 & 1.5 & 345 & 0.07 & 142 & 22 & 0.14 \\
\hline 11 & 22 & 37.6 & 024 & 13.1 & 22 & 0.14 \\
\hline 12 & 1.9 & 24.3 & 0.18 & 20 & 1.9 & 0.13 \\
\hline
\end{tabular}

TABLE 2

\begin{tabular}{|c|c|c|c|c|c|c|c|c|c|}
\hline \multirow[b]{2}{*}{ Putern } & \multicolumn{9}{|c|}{ Doso in med/mct } \\
\hline & $\begin{array}{l}\text { Whole } \\
\text { Body }\end{array}$ & $\begin{array}{l}\text { Elood } \\
\text { in } \\
\text { Bloced }\end{array}$ & $\begin{array}{l}\text { Marrew of } \\
\text { Merrow } \\
\text { (megingl) }\end{array}$ & Uver & Spleen & L Kodney & A. Koiney & L Lung & R. Lung \\
\hline 1 & 0.40 & 0.22 & $M$ & 2.01 & 22 & 200 & 220 & MA & NA \\
\hline 2 & 0.40 & 1.84 & acs & 7.81 & ses & 123 & 1.39 & 1.98 & 208 \\
\hline 3 & 0.30 & 0.00 & Q.40 & 8.0 & e.e. & 237 & 358 & 22 & 244 \\
\hline 4 & 0.42 & 1.00 & 270 & 1.92 & 8.44 & 1.87 & 20 & 1.32 & 1.39 \\
\hline 5 & $\infty$ & $a \infty$ & $12 n$ & 8.40 & 4.50 & 1.10 & 1.10 & MA & MA \\
\hline - & ass & 0.44 & ans & s.17 & 5.00 & 1.40 & 1.00 & 0.4 & 0.93 \\
\hline 7 & 0.40 & a.es & 247 & MA & 1201 & 0.00 & 0.03 & 1.01 & 1.31 \\
\hline 8 & 0.42 & ase & 20 & 5.1 & 7.40 & 1.10 & NA & Na & Na \\
\hline 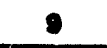 & a.4 & 0.40 & 0.10 & 0.01 & 4.14 & 1.50 & 1.34 & 224 & 243 \\
\hline 10 & 0.49 & 0.40 & 20 & 5.41 & spim. & 220 & $2 \pi$ & 302 & 420 \\
\hline 11 & 0.49 & 120 & $a x$ & 4.00 & epter. & 207 & 207 & 1.00 & 1.84 \\
\hline 12 & 0.5 & 0.0 & 0.18 & 4.10 & 3.08 & $1 . \pi$ & 1.70 & 240 & 240 \\
\hline
\end{tabular}

MA = Not cunileblo

coler - equenoctomy 


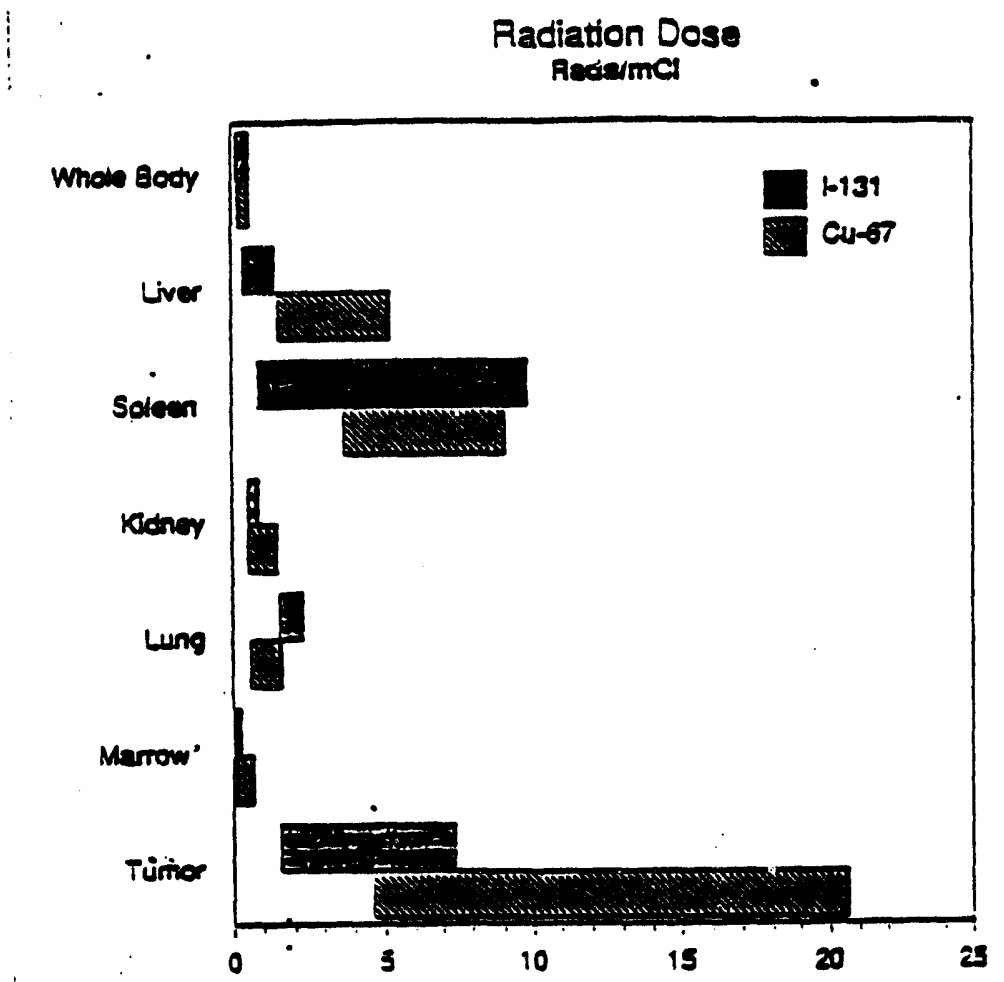

Bloced ano wnove booy

Figure 4. Comparison of radiation dosimetry for ${ }^{131} / \mathrm{Lym}-1$ and 7 Cu-BAT-Lym-1 in patients.

\section{1 hPYY-2T-BAD MOAb}

The macrocyclic chelating agent 1,4,7,10-tetraazaocyclododecane-N,N',N",N"'. tetraacetic acid (DOTA), developed by Meares and coworkers as a carrier for ${ }^{50} Y$ (93) has been shown to stably bind "1" in as well. In collaboration with Fand (94), we have shown that the skelotal uptake of ${ }^{5} Y$ in mice was negligible when bromoscetamidobenzyH-DOTA (BAD) was used compared to that when cyclic antydride DTPA wes used to prepare Lym-1 radioimmuno-conjugate. It seemed appropriate to evaluate the signilicance of ${ }^{20}$ escape from radioimmunoconjugates on the does-limiting marrow toxicity by comparing the macrocyclic chelator, BAD (DOTA), with MX-DTPA, a chelator generally regarded as one of the better ones for ${ }^{\text {DO }}$. Survival in mice was used as the primary endpoint and blood counts were used to provide mechanistic and inferential radiation dosimetric information. (BrE-3 (a mouse IgG1 antbody to a 20 amino acid tandem repeat sequence of mucin) $(95,96)$ is an anti-breast cancer MOAb developed by Dr. Roberto Ceriani and formulated with $M X$ DTPA by Coulter Immunology for clinical trials). 
FIGURE 5

Survtral of Balbre Mice Given

Y.90 arE-3-2IT-BAD or Y-90 BrE-3-MX-DTPA

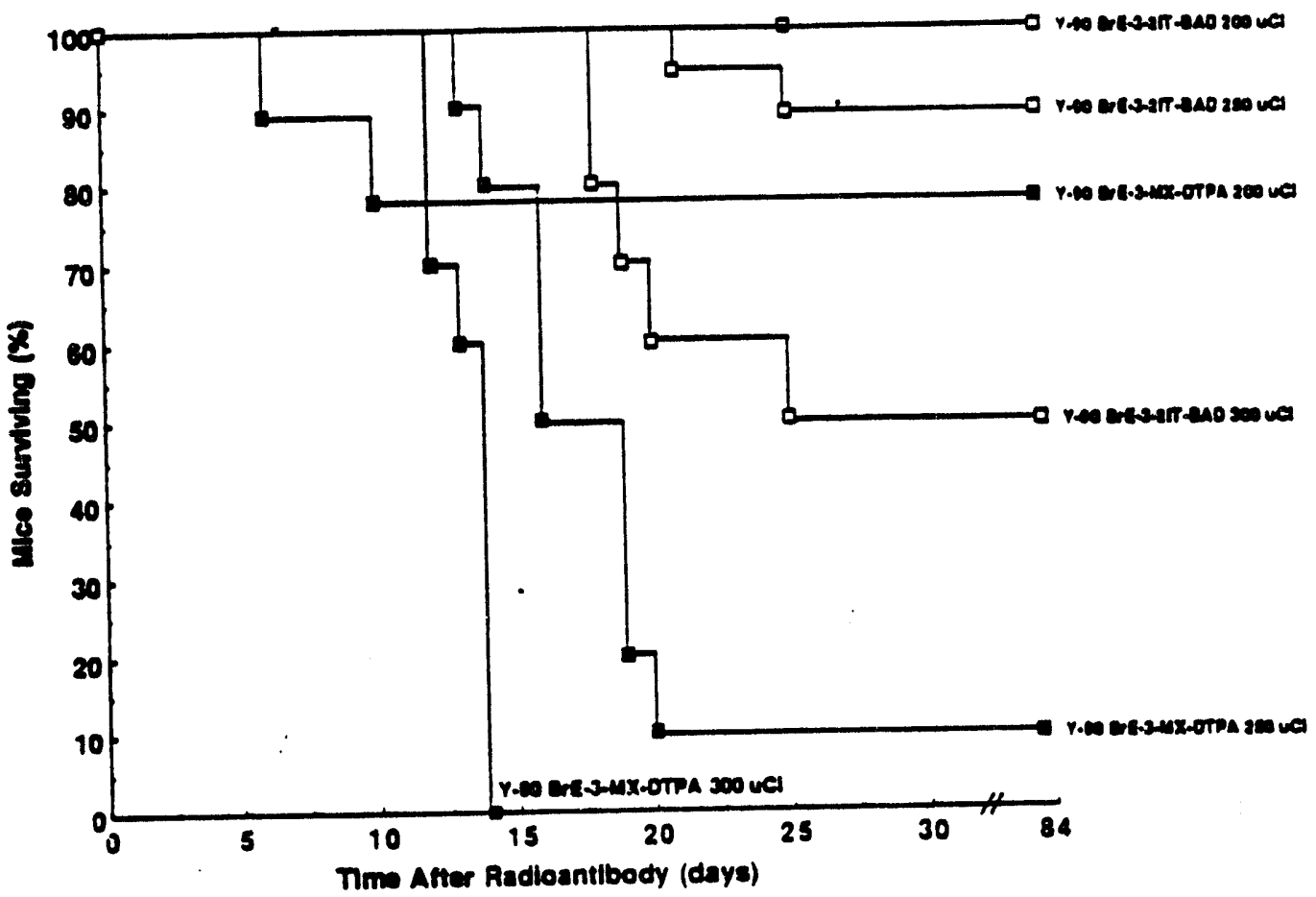

Suntval of mice after injection of POY-BrE-3-MX-DTPA or 90 Y-BrE-3-2यT-BAD.

Figure 5 shows the comparative survival curves for two groups of mice given similar amounts of either radiopharmaceutical. The $L_{50}$ for $M X-D P T A-B r E-3(221 \mu C i)$ wes lower than the $L D_{30}$ for $2-\pi-B A D-B r E-3(308 \mu C)(97)$. In order to explain the difierence, biodistributions of the two radiopharmaceuticals were examined using whole body autoradlography (WBAR) on sections of mice. This data indicated more ${ }^{\text {so }}$. escaped from the MX-DTPA chelate than from 2T-BAD. The tree oy was incorporated into bone matrix giving a higher dose to the marrow, which explains the higher $L_{s o}$ for our $2 \pi$-BAD-BrE-3. Other investigators $(94,98,99)$ have reported an $D_{s 0}$ tor MX-DTPA radloimmunoconjugates comparable to that observed by us while Buchsbaum $(100)$ reported a somewhat higher $L D_{50}$. Investigators have uniformly reported that "o, whon chelated to antibody with cyclic anhydrides, had uptake in bono 3 - 5 times greater and an $L_{50}$ soveral tmes less than that for benzyl DTPA and MX-DTPA (101103). When comparing benzyl DTPA and MX-DTPA soy-immunoconjugates, Washbum (101) estimated radiation doses to the bone and marrow that were 12 - 45 percent less for the "new generation" of chelates than for the cyclic anhydride chelate. Washbum (101) concluded that there was "still a definite need for turther improvements in bifunctional chelate technology in order to maximize tumor uptake and minimize uptake in radiation-sensittve normal organs." While benzyl DIPA chelates have been shown to be superior to cyclic anhydride DTPA chelates, Sharkey (104) observed suticient oy escape from an MX-DTPA radioimmunoconjugate to lead him to conclude that the MTD of ${ }^{131}$ / $\mathrm{imm}$ unoconjugate would deliver 5.9 times the dose to the.tumor xenograt in mice as would the MTD of the same immunoconjugate. DOTA and our new conjugation methods, revorse this relationship. 


\section{${ }^{111}$ In-2T-BADLym-1 Feasibilty Studies in Lymphoma Pationts}

111 In DOTA Lym-1 has been studled in lymphoma pattents (105) for imaging/pharmacokinetic studioe. Tumor uptake was excellent and no immunological problems wore seen.

Proparations ranged from $0.5-0.9 \mathrm{mCV} / \mathrm{mg}$ and iminunoreacthity from $90-100 \%$ that of unconjugated Lym-1. Imaging of ${ }^{111}$ In-2rT-BAD-Lym-1 was superior to that of ${ }^{131} 1$-Lym-1. Blood clearances of the 2 radiopharmacouticals were similar but the peak tumor to blood ratio of 111 In-2rT-BAD-Lym-1 was up to 5 times greater than ${ }^{131} 1$-Lym-1. Marrow dose from blood was

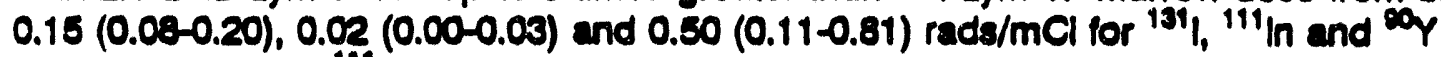
(extrapolated from ${ }^{111}(\mathrm{n})$, respectively. Howover, DOTA used in large quanttles with murine MOAb in ovarian cancer patients by another investigator generated ant-DOTA human antibodies in these pationts (100). On the other hand, autologous moriomeric antbody-DOTA conjugates in rabblts have not stimulated production of antl-DOTA antbodies to date. This data suggests that DOTA is only immunogenic when given in combination with immunogenic stimull such as foroign proteln (mouse MoAb) and/or high molecular wolght aggregates of the antibody molecules. These triggers may direct the immune system to "see" the macrocycle as well. DOTA laboled humanized MOAb with no high molecular woight (complex) component should have little or no immunogenicity in clinical trials.

\section{arpepido DOTA MoAb}

Recently, by directly coupling a tetrapeptide to DOTA via an amide bond Dr. Meares' group has syntheaized a novel DOTA dertvattve, DOTA-glycyl-glycyl-glycyll-pnitrophemylalanineamide. This has been converted to bliunctional chelating agent DOTAglycyl-glycyl-glycyl-L-(p-ieothiocyanato)phenylalanineamide and conjugatod to Lym-1 and ChLo (peptdde-DOTA-MOAb). Serum stability studles show that the radlolabeled conjugates are kinetically inert under physiological conditions (107). The rates of loss (\%/day \pm 1 SD) of radiomotals in human serum are: ${ }^{6} Y, 0.02( \pm 0.15) ;{ }^{114 m} / n, 0.1( \pm 0.1) ;$ and ${ }^{6} \mathrm{Cu}, 0.29( \pm 0.10)$. In the presence of the enzyme cathepsin $B$ which is abundant in hepatocytes, an in vitto digestion of ${ }^{114 m} / \mathrm{n}$ labeled conjugate yields a small tragment containing DOTA ${ }^{114 m} / \mathrm{n}$. Characterization of the cleavage products showed that the enzyme hydrolyzed the peptide linkage. In vivo studies of ${ }^{111}$ In and 9 Y.peptide-DOTA ChL6 have contirmed these usetul properties as uptake and retention in the liver were less than that of other radiometal immunoconjugates (including 2T-BAD-1.ym-1) while tumor uptake and rotention were high, bone uptake was negllgible and, blood and body clearances were similar to the radiolodinated control. Compared to rudioiodinated ChLE, mouse studies have demonstrated a substantially enhanced therapeutic index (Figures 6 \& 7 ).

In SYY radiolabeling of 2IT-BAD-Lym-1, most binding sites (conjugated DOTA moieties) on the immunoconjugats are complexed by motal ion contaminants of ${ }^{\circ} \mathrm{Y}$ solution. This limits the specific activity of the radiolmmunoconjugate and necessitates a large excess of DOTA sites relattve to "ry for radiolabeling. To optimize the specific acthity of the radioimmunoconjugate and minimize the number of DOTA binding sites because of presumed antigenic potential, a novel approach has been devised for the preparation of radioimmunoconjugates. PeptideDOTA was laboled with the trivalent radiometals ${ }^{111}$ in or oy and purtiled on an anion exchnage column to remove peptide-DOTA chelated to other mtal ions. The purtiled radiolabeled chelates wore of very high specific activity; in the case of 2 Y-peptide-DOTA, 50 $\mathrm{mCl}$ oY/mg peptldo-DOTA. The purtiled radiolabeled chelates were thon conjugates to ChL6 at ratios of leas than 1 peptide-DOTA per ChLE. These preparations were used for the animal studies deacribed (Figures $6 \& 7$ ) and will be developed into pharmacologic preparations for human pharmacoutical and dosimetry studies. 
FIGURE 6

A. ORGAN UPTAKE OF ${ }^{12 \%}$ LChL6 IN TUMORED MICE

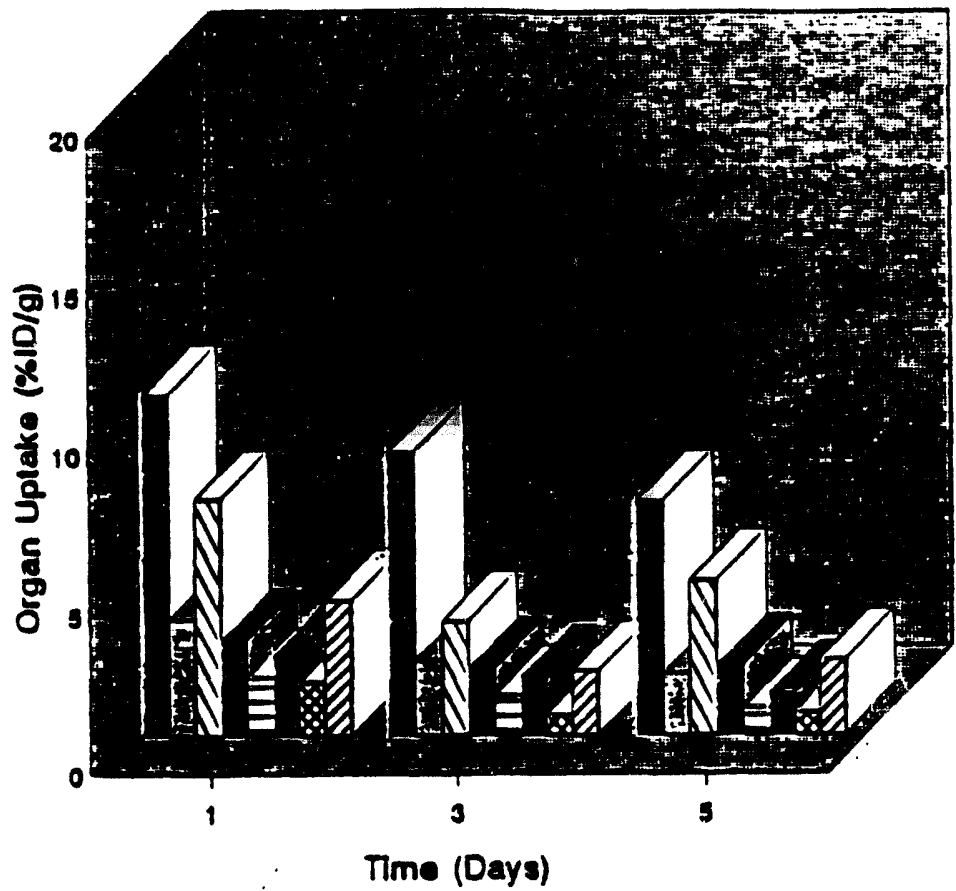

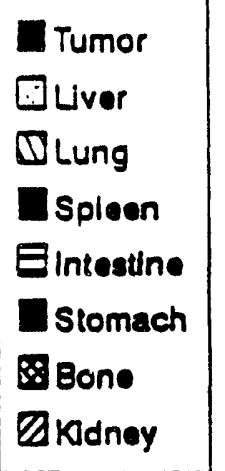

B. ORGAN UPTAKE OF SYYPEPTIDE-DOTA-CHLG IN TUMORED MICE

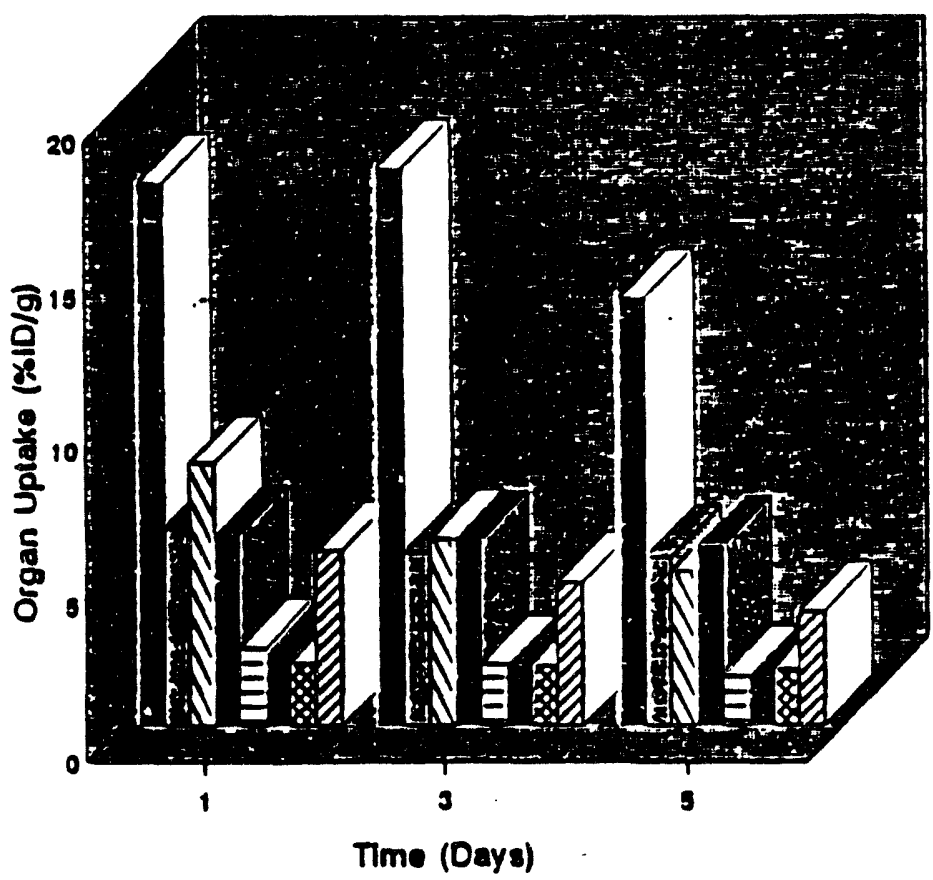

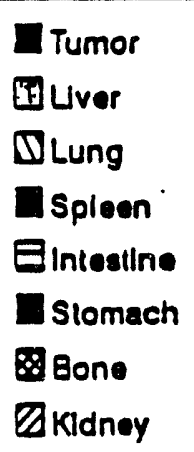

Tumor and organ uptake over time. Tumor uptake and retention of Poy-peptide-DOTAChL6 was greater than that of ${ }^{125}$-ChL6 in tumored mice without corresponding differences in normal tissues such as bone. 
Uptake and residence time of 9 Y-peptide-DOTA-ChL6 in the liver and body clearance were comparable to ${ }^{131}$ 1-ChL6 in mouse studies, suggesting that the therapeutic index can be enhanced by a factor of 3 by using ${ }^{90}$ Y peptide DOTA ChL6 rather than ${ }^{131}$ / ChL6.

FIGUAE 7

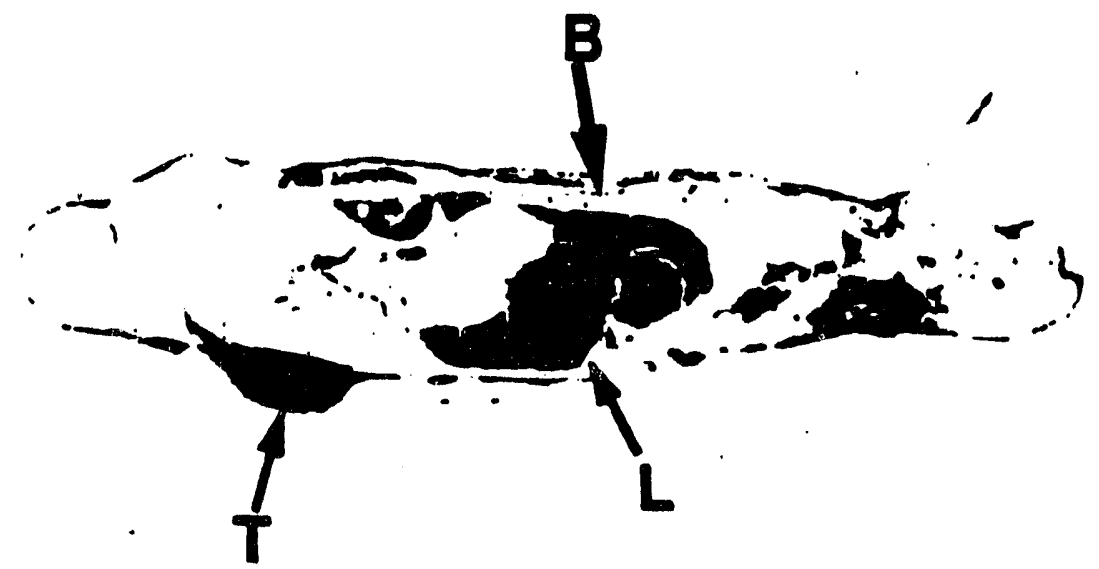

Radioautograph of tumor bearing mouse 48 hours after PY-peptide-DOTA-ChL6 demonstrates absence of bone (B) uptake of ${ }^{\circ} \mathrm{Y}$, intense and homogeneous tumor $(T)$ radiation and modest IIver (L) activity.

\section{Surties of Biologic Activation Associated with Molecular Receptor Increase and Tumor Response in ChLe/6 Protocol Patients}

Several patients in these studies had superficial tumors which developed evidence for inflarmmatory reactions manifested by warmth, erythema, and/or tenderness within a fow hours of intusion of uniabeled antibody. These findings led to a study of several parameters of biologic systems activation associated with ${ }^{131}$ / ChL6 treatment. Complement activation, ADCC enhancement of NK and monocyte/macrophage PBMN's, IL-1, IL-2, and IL-2 receptor (IL-2R) levels in serum, serum albumin, tumor uptake and radiation dose were examined to evaluate the role of synergy between the biologic systems and the radlation leading to therapeutic responses. In the first 10 therapy patients, C3, C4 and albumin levels fell during both $L 6$ and ChLe intusions and remained below normal for hours to days post therapy. Pationts in the antboody dose escalation study receiving proload doses of 50, 100, 150, or 200 $\mathrm{mg}$ of Le did not demonstrate a significant increase in their IL-2 receptor lovel unless $150 \mathrm{mg}$ or more had been given. The first 9 patients receiving imaging and therapy intusions on sequentlal days demonstrated a dose and time dependent increase of soluble IL-2 receptor levels in serum when compared to preinfusion baseline lovels. In 2 patients, IL-2 levels were elevated shortly atter initiation of the intusion of L6 or ChL6. IL-2 levels, however, could not be detected by the assay once the IL-2 receptor level had risen. Levels of IL-1 a varied in the 9 therapy patients and many decreased after the initial $200 \mathrm{mg}$ of L6 or ChL6 $(108,109)$. The dosimetry from the studies suggests that there may well be synergy of tumor cell kill from the effects of combined low level irradiation with biologically triggered molecular events in the cell. These effects will be further investigated in the molecular biology studles proposed for the next grant period. 


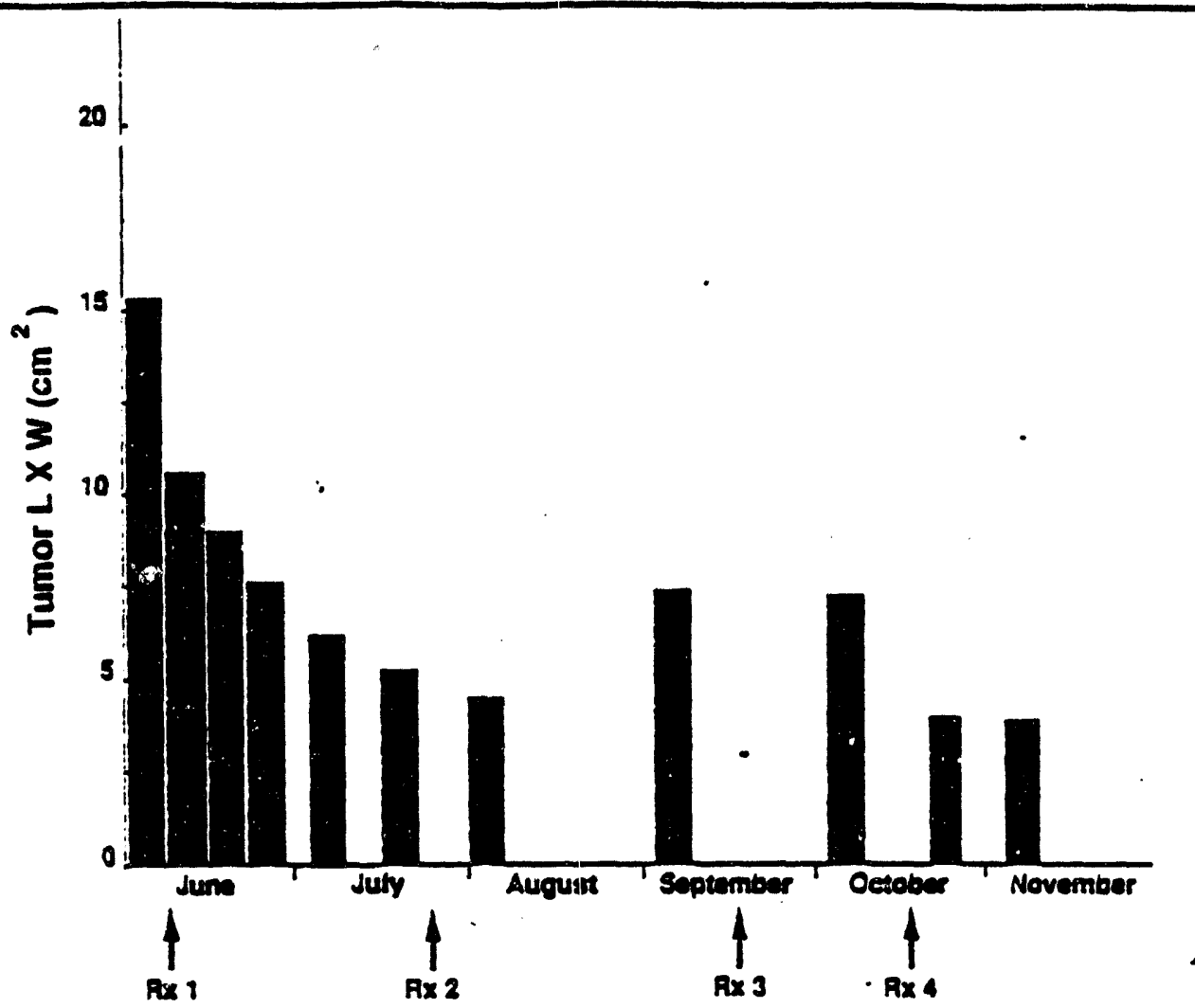

Figure 8. Therapy course of a patient demonstrating regression of her tumor in reaponee to ${ }^{131}$ I ChL6 therapy doses (Px 1-4). All measurable tumor areas are graphically shown as the sum of the products of their longest dlameter and the greatest perpendicular diameter obtainied from caliper measurements taken by two physicians before therapy and at frequent intervals after each of her therapy doses.

In conclusion, these findings suggest that the biologic activity of L6 and ChL6 in vivo was responsible for enhanced tumor uptake of $131 /$ ChLe in many of our patients secondary to transient, increased vascular permeabillty without signilicant adverse clinical sequelae. Complement activation and $11-2$ receptor release may have been triggered by separate mechanisms. Tumor response was seen more frequently in thia study than in any previously reported study using radioimmunoconjugates in solid tumors (Figure 8). Because of the correlation of IL-2R rise to the tumor response and relatively modest radiation doses in soveral responding tumors, wo postulate that responses may have been secondary to synergy between enhanced deffvery of the targeted radiation and sensitizing effects on tumor caused by activated effector cell mechanisms. Clinical studies of L6 and ChL6 alone had minimal to no therapeutlc response (110-112).

\section{Lym-1 Single Chain Genetically Enginessred Molecules}

Lym-1 recognizes a cell membrano-tocated antigen on human hymphoma cells that has a molecular weight of $31.35 \mathrm{kD}$ and is not shed or modulated (113). Lym-1 is highly B cell specilic cross reacting only slightly with surfacis epithelial colis of the colon and macrophages of the skin; it rescts preferentially with malignant B cells. Lym-1 dses not react with normal or malignant T cells, but does react with a broad range of B tumor cell lines, $40 \%$ of specimens from patients with B cell chronic lymphocytic loukemia and at least $80 \%$ of specimens from pattents with B cell hymphoma (113). The number of binding sites per Rail 8 hymphoma cell was found to be $1 \times 10^{\circ}$ and the avidity constant was found to be $4 \times 10^{2} M^{-1}$ for Lym-1 (113).

$$
\text { Page III }
$$


In the low fractionated ${ }^{197}$ /-Lym-1 therapy study initiated as a pationt fesaibility study under this grant, 17 of 30 of Lym-1 reactive patients had durable responses (114). In the maximum tolerated dose ${ }^{139}$ HLym-1 study, 13 of 24 patients had durable responses including 8 complete remissions (115). The radiation dose-fimiting toxicty was thrombocytopenia (110). Others have confirmed the responsiveness of pattents with hematopoibtic malignancies using this agent (117), and other radiolabeled antibodice alone (118-123) and in asecciation with bone marrow transplantation (124). While these trials proved succeastul, they also demonstrated the need to enhance the conditions for treatment in order to more generally achieve longer remisaions or cure.

The first step in the production of the gene expressing the Lym-1 SCA was sequencing of the mRNA from the hybridoma cell encoding the murin monoctonal antibody Lym-1. Primers were then deaigned to comvert the maNAs encoding the heavy and light chains to CDNAs. A second set of primers were deaigned to use in Polymerase Chain Rasetion amplification of the CDNA. The primers also incorporated restriction enzyme endonuclease cleavage sites at the ends of thees stretches to use for the ligations to aseomble the gene. The encoding of the segment linker peptide was prepared from two single stranded lengths of synthesized DNA, which were annealed and converted to double stranded DNA, and also cut with restriction enzymes so that they could be ligated between the $3^{\prime}$ end of the light chain $F_{v}$ gene and the $5^{\prime}$ end of the heavy chain $F_{v}$ gene. A hybrid operator/promoter site was produced in a similar fechion. The gene was cut at the ende with restriction endonucleases EcoRl and Bamill and put into plasmid pUCs for transformation of tho hosts. Tho $E$. coll hoots initially used to expreas this protein have the c1867 temperature sencitus lambda repreasor mutation so that they can be grown at $29^{\circ} \mathrm{C}$, and then protoin expression induced by raising the temperature to $42^{\circ} \mathrm{C}$. Several variations of this SCA have been produced and are currently being purtied for further evaluation.

\section{Anabrib of Molecular Genetic Coded Messages to Enhence Tumor Response}

In order to consider other agents or targets for molecular triggers which may enhance the sensitivity of the tumor coll by enhancing death when combined with low dose rate radiation delivered by targeted therapy, selected genetic expression profiles are being studied in nude mouse human tumor xenograph models. Expression of apoptosib-essociated (TGFB 1, p53 TNF), cytokine (IL-6, IL-2, IL-22) and prognosis-associated (NMP3-HI, MDR-1) genes will be monitored in studies planned to determine the $L D_{50}$ of 59 DOTA peptide ChLe in nude mice with human breast tumors (HBT) and 90 Y DOTA peptide H170 in nudo mice with MCF.7 tumors. Potential enhancement of radioimmunotherapy by low dose tamoxfien, and peptides blocking other growth receptors, will be ovaluated in theas breast cancer modele and correlated to mPNh expreasion of genes listed above. The methodology for the tumor genetic expreselon pand was developed under current funding and each selection has boen shown to have a relationship to radiation or hormone triggered programmed cell death or pattent prognoais $(43-46)$. Wo will compare pattoms of tumor response to variations in these mANA levels. It is hoped that exploration of molecular mechanisms related to tumor cell death can lead to tuture studies of combined agents from which can determine synergistic triggers for programmed cell death in tumor colls.

During the past two years, wo have reined our quanttative RNAPCA assay. Samples are run in triplicate PCR reactlons for each gene analyzed and dot blotted with subsequent nonisotopic probing. Adapting to the dot blot allowed us to reduce variability to 14\%. An examination of human cancers for expression of the NM23 family (NM23-H1 and H2) revealed a significent decrease in NM23-H2 as cancer stage increased. This manuscript has been submitted. Wo have also studled levels of MDR-1 expression in human tumors using this 
approach (125).

6. Human Dosimetry and Therapeutic Human Usa Radiophamaceuticalo

MOAb radiopharmaceuticals prepared for dosimetry or therapeutle feasibility (human use) during this perlod of report are presented in the following Tablo.

TABLE 3

\begin{tabular}{|l|rr|rr|}
\hline \multirow{2}{*}{ Radiopharmaceutical } & \multicolumn{2}{|c|}{ Imaging } & \multicolumn{2}{c|}{ Therapy } \\
\cline { 2 - 6 } & Doses & $\mathrm{mCl}$ & Doses & $\mathrm{mCl}$ \\
\hline${ }^{7}$ Cu-2T-BAT-Lym-1 & 12 & 98 & 8 & 680 \\
${ }^{119}$ In-2T-BAD-Lym-1 & 5 & 24 & $\mathrm{NA}$ & $\mathrm{NA}$ \\
\hline
\end{tabular}

NA Not applicable.

Numerous in vivo experiments wore 3130 conducted in both tumored and non-tumored nude mouse models. Blodistribution studies wore conducted in both tumored and non-tumored mics for the assesement of chemical stablity, in vivo kinotics and procesaing (motabollem/catabollem) and toxicty of the radiopharmaceuticals. Other studiea were carried out in tumor modele with the objectives of simulating therapy and obtaining information on the therapeutic enhancement mechanisms. A summary list of all the animal study preparations is presented in the following Table. 
TABLE 4

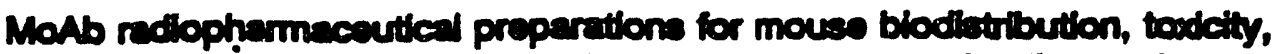
therapy and iutoradiography studies during the current funding period.

\begin{tabular}{|c|c|c|c|}
\hline & Blodistribution & Therapy & Autoradlography \\
\hline Radiopharmaceutical & uCl & uCl & $\mathrm{uCl}$ \\
\hline 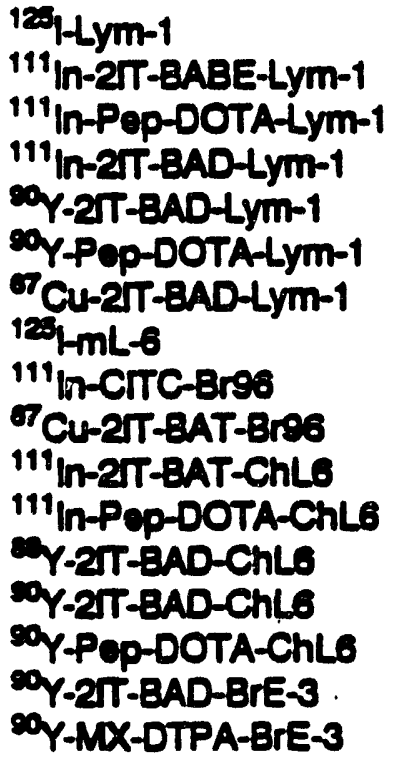 & $\begin{array}{r}3084 \\
272 \\
272 \\
905 \\
- \\
175 \\
80 \\
3821 \\
150 \\
- \\
1452 \\
1200 \\
85 \\
745 \\
765 \\
- \\
700\end{array}$ & $\begin{array}{r}- \\
\overline{-} \\
460 \\
\overline{-} \\
\overline{-} \\
20379 \\
168 \\
- \\
- \\
- \\
11600 \\
8300\end{array}$ & $\begin{array}{r}616 \\
- \\
- \\
\overline{-} \\
1100 \\
- \\
- \\
\overline{-} \\
1000 \\
550 \\
- \\
2260 \\
- \\
\overline{-} \\
70 \\
300\end{array}$ \\
\hline
\end{tabular}

Information generated by animal experiments with these radiopharmaceuticals has been used in planning our clinical dosimetric/biokinetic and therapy feasibility/toxicity protocols. Some studies have also been published (126-131).

\section{STUDIES IN PHANTOMS}

Pianar Image Quentitation. A primary concern for this project is to continuousty improve the quantitative planer imaging mothods used by our group. During this past grant period studies included validation of image quantitation methods in organs and tumors. Coincidence correction and quantitation of ${ }^{\text {or }}$ using bremsstrahlung imaging wore also studied.

Counts Coincidence Correction. Due to counts eoincidence, significant errors have been found in image counts over the therapeutic range of ${ }^{131} /$ and ${ }^{\circ} \mathrm{Cu}$. At an injected dose level of $100 \mathrm{mCl}$ of ${ }^{\circ} \mathrm{Cu}$ in the patient, tho total observed count rate by the dual detector camera. (Siemens Bodyscan) reached a maximum of $140 \mathrm{~K}$ counts per second. The count loss in an image of the chest or abdomen was over $70 \%$ of the true counts. Mothods have been explored to correct planar gamma camera static images of an abdominal phantom for the resolving time errors encountered with the gamma camera. 'A simple mothod was cvaluated in which a $10 \mathrm{ml}$ reference source containing about $200 \mathrm{\mu Cl}$ was imaged in the same field of view of each patient image. The number of counts from the reference source was expressed 
as a ratio of the counts detected from an image of the source in air alone to the counts from the roference source in the pationt image to determine the count lose for each trame. Errors in correction may occur when the photopeak shape and postion are not preserved using this method. Validation of this reference source method on the Siemens gamma camera was performed using ${ }^{8} \mathrm{Cu}$ concentrations similar to those of therapy doses in a phantom. The quanttation errors of this correction mothod were reasonably small. At an injected dose level of about $100 \mathrm{mCl}$ of ${ }^{\circ 7} \mathrm{Cu}$, the count loss in an abdominal image was estimated to be greater than $70 \%$ of the actual counts. This loss of counts was corrected with an accuracy within 15 $\%$ using this simple correction mothod.

Organ Suctea. In order to provide a basis for radiation dosimotry in planning targeted molecular therapy, it was necessary to validate the quanttattve mothods used. Planar imaging mothods for quantitating ${ }^{120} 1$, sein TC, and ${ }^{111}$ In in the liver and spleen of the abdominal phantom were asseased using a gamma camera. In the first approsch, the number of counts detected in a single image of the liver or spleen was used to measure radionuclide content using an attenuation correction factor (ACF) calculated from data obtained without radioactivity in the background volume of the phantom. In two other methods, radionuclide content was derived from either the geomotric mean (GM) of counts in conjugate images or in individual, opposed pixels of the conjugate images. The influence of background counts on quantitation was studied by adding a moasured concentration of radioactivity to the background cavity of the abdominal phantom. The best estimates of radionuclide content were obtained by quantitation from the GM of counts in conjugate images of the liver and spleen. Radionuclide content of the liver and spleen could be determined from a single image if an appropriate correction for attenuation was available. These results provided a basis for radiation dosimetry for these and similar organs in patients.

Tumor Studica. Determination of the actual dose to tumors is important in evaluating the efficacy of a radiolabeled molecular construct. Accurate planar quantitation for tumors is made dificult by their relathely small size and radionuclide content when compared to surrounding larger organs and high background activity found in tissues. Umited studles on planar quantitation of ${ }^{131}$ l in tumors have been previously reported. Quantitation of the size and amount of uptake of ${ }^{131} \mathrm{I}$ in tumors was investigated in order to obtain the best threshold with variation in activity concentration, source size, tumor depth and background activity using an Alderson abdominal phantom (132). Better quantitative accuracy was established when a deeply seated tumor was quantified using the geometric-mean of conjugate viow method and when a supericial tumor was quantfied using the effective point source method. The accuracy of estimation of radionuclide amount was within $10 \%$ for $3-5 \mathrm{~cm}$ tumors and was better than $20 \%$ for $a 1 \mathrm{~cm}$ tumor at all tumor and background concentrations and locations in the phantom.

oy Quantitution With Bremsstrahlung Imaging. Studles of co quantitation using bremsetrahlung imaging have been conducted to predict the behavior of soy in-vivo. Conventional gamma photon imaging mothods cannot be simply applied to imaging of the bremsetrahlung continuous energy spectrum. The. spatial and enorgy dependence of bremsstrahlung production cause an inherent limitation in spatial resolution for bremsstrahlung imaging. While high energy photons are created near the decay site, most low energy bremsstrahlung photons are produced farther from the of decay location (133). On the other hand, degradation of the bremastrahlung image is, in part, due to septal penetration from high energy photons of the continuous energy spectrum from soy decay. These photons are accepted in the selected energy window as Compton scattered events in the camera cystal. The energy distribution of Compton photons within the selected energy window infiuences image resolution. The choice of collimation and energy window represents 
a practical compromise between sensituity and spatial resolution requirements for specific cireumstances. The dotector system sensitivity, resolution and image S/N were investigated for various collimators and energy windows. Studies on accuracy of quantitation of ${ }^{\circ} Y$ activity in an Alderson abdominal phantom have also been performed ueing the geometric mean of conjugate view or effective point source methods (134). To overcome problems of unclear visual boundaries inherent to imaging of bremsstrahlung a contrast recovery mothod was developed. Mothods of quanttlattve bremsstrahlung imaging have been enhanced by the use of a Wiener filter to deconvolve the septal penetration and scatter (Figure 9).
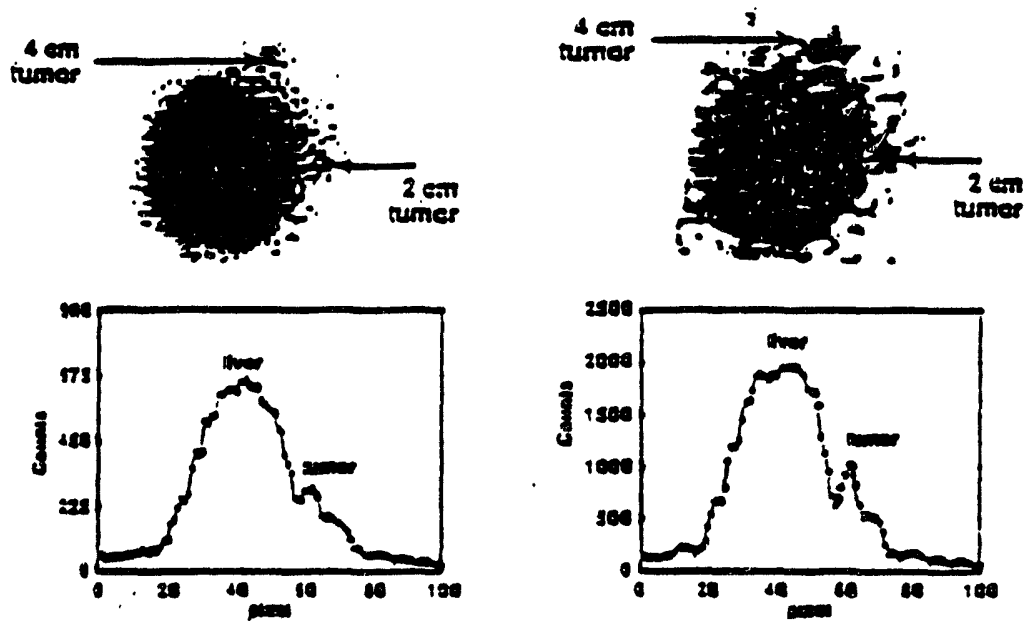

Figure 9.

Comparison of anterior phantom images and line profiles before (left) and after (right) Wener filtering. Tumor definition was enhanced on the images (top lett and right) as shown by the difference in the line profiles (bottom left and right).

A three-fold improvement in resolution recovery was achieved for full width at tenth maximum of a 9 y line source when placed in $10 \mathrm{~cm}$ of water. Tumor definition was facilitated after Wiener filtering. Tumor and organ quantitation on filtered images in a phantom study yielded an estimation accuracy of better than $10 \%$ for cumulated activity in the liver, spleen and $4 \mathrm{~cm}$ tumor. These results were comparable to those obtained from a single photon emitter such as ${ }^{191} /$ using planar imaging (135).

\section{QUANTITATIVE SPECT}

The intrinsic dificulty in planar quantitation is background subtraction when organs are superimposed. SPECT effectively ellminates the problems of superimposition of organs and tissues and improves target to non-target image contrast. SPECT has the potential to quantify radlonuclide and mass with greater accuracy in comparison to planar imaging. Practical SPECT messurement of radionuclide content requires: 1) accurate determination of camera sensittvity; 2) accurate definition of region of interest to determine the number of counts within it; 3) correction for attenuation; 4) correction for scatter and septal penotration; 5) accurate measurement of the administered dose; 6) adequate statistica; and 7$)$ accurate definition of tissue mass or volume (130). We have made substantial progress in dealing with these issues especially in the areas of photon attenuation and scatter correction. 
Attonumiton Correction. Quantitative tomography must address the requirement for accurate boundary dotermination in each tranoverse section and greater senaitivity to errors in the attenuation correction. First, we have investigated improved methods of boundary definition for attenuation correction in SPECT. Three Compton scatter mothods have been investigated using a source of "inTc (137). The so-degree Compton scatter method was found to give the best boundary definition. This mothod entails the use of a source (that does not superimpose any part of the patient or phantom) placed 90 degrees to the front of the detector. We have also investigated a modified post processing correction matrit for photon attenuation correction (138). When the tranoverse section imagea were corrected for attenuation the liver and spleen were similarty elevated by the same scatter fraction. The post reconstruction correction r.ratrtx generated with the narrow beam linear attenuation coefficient value of $0.15 / \mathrm{cm}$ for the $140 \mathrm{koV}$ photons emitted by the $\mathrm{mm}$ Te callbration source was used in this method. When this correction wes applied to. the phantom sources, the radionuclide content of the liver and spleen was determined with bettor than $10 \%$ sccuracy.

Scatter Correction. One of the principal obstacles in the use of SPECT for absolute quanttation has been the inclusion of a large fraction of the counts that arise from scatter detected in a reglon of interest that outline the boundary of an organ on a transverse section image provided by SPECT. The scattered events that originate from the source activity are added to scatter from all other sources that are inside and outside any particular transverse section both inside and outaide the direct field of viow of the camera. Since Jaszczak (68) proposed a mothoc to eotimate the scatter ovents using count in a scatter window, scatter subtraction has received a lot of attention because of ths effectiveness and practicality. Because the scatter ovents in the energy window is also related to the photons emitted from higher energies (og. ${ }^{131}$ I $637 \mathrm{keV}$ scatter to $364 \mathrm{keV}$ window, ${ }^{7} \mathrm{Cu} 184 \mathrm{keV}$ scatter to $93 \mathrm{keV}$ window), it is more reasonable to estimate scatter events using a dual scatter window above and below the photopeak. .

Because of the high energy and significant septal penetration with ${ }^{131} 1$, correction factors must be determined that are unique to this radionuclide. A primary energy window of $15 \%$ ceritered at $364 \mathrm{keV}$ was selected for the primary photopeak. Two scatter windows above and below the primary energy window were used for collecting scatter photons. The image from the scatter window was subtracted from the primary photopeak image before reconstruction of the images was done, and Chang's attenuation correction mothod (67) was subsequently applied. With this scattor subtraction method, we were able to quantify activity in the liver phantom as well as volumes of both the liver and spleen with better than $10 \%$ accuracy. We also estimated volumes with an accuracy better than $90 \%$.

Accurate quantitation of ${ }^{67} \mathrm{Cu}$ is aleo necessary to depict the blodistribution of these radiolabeled targeted molecules in patients. While the primary photon emission energies of ${ }^{\circ} \mathrm{Cu}$ at $93 \mathrm{koV}$ and $184 \mathrm{koV}$ are more suitable for imaging than those of ${ }^{131} \mathrm{I}$, its dual photopeaks rales lesues in quanttattve imaging different from other radionuclides. Scattor subtraction was performed on projection data using measured $k$ scatter values for the 92 $\mathrm{keV}, 184 \mathrm{koV}$ energy windows and for a combination window around each of the 92 and 184 koV photopeaks. Attenuation correction was performed with the linear attenuation coefficient ineasured from either a rod transmission scan or transmission fraction data from a small volume source in water. We found that image quality or quantitation results obtained using the $184 \mathrm{keV}$ energy window were generally better than with either the $92 \mathrm{keV}$ or combined 92 and $184 \mathrm{keV}$ energy windows. However for a single detector SPECT system, the combination window should be utilized when counts are low e.g. for acquisition times of less 45 minutes when the remaining activity in the pattent is less than $4 \mathrm{mCl}$. 


\section{Priecuman STUDIES}

The goal of performing preclinical studies is to provide experimental models of human diseases in mice to optimize molecular targoting and thorapy for cancer. First, quanttation intormation on organ and tumor uptake of targeted molecules provides basic criteria for oveluating therapeutic efilcacy and toxjecty. Wholo body autoradiography has been shown to be a powertul tool in quantfation of uptake of radioactivity. Second, previous studies demonstrated that the offectiveness of radiolabeled targeted molecular therapy depends on a number of factors relating to the targoted molecule such as specticity, aftinity, and immunoreactivity (130). The denaity, location, and hoterogeneity of molecular distribution within tumors have signilicant offects on therapeutic efficacy. One of the obstacles for cancer therapy with radiolabeled targeted molecules is the problem of tumor penetration. The. efiectivences of ancer cell killing is hindered by hoterogenoity of the radiation dose in tumor. The study of this hoterogeneous radiation dose is obesrved by imaging. Spattal resolution of SPECT is in the order of several millimoters and therefore is limited to yielding information at mecroscopic levels. Autoradiography provides a good opportunity for evaluating molecular blodistribution at a tiasue level. The information obtainod from autoradiography is fundamental to understanding and improving the behavior of these molecules in tumors and normal tiseues.

Wo haw invertigated uptake of PY-BrE.3 in mice using autoradography. PY is a promising therapeutic radionuclide and reduces the problem of dose hoterogeneity in small tumors because of ths long range bota emission. Padiation dose to the tumors in mice was anticipated to be uniform. However, therapinutic trials demonstrated escape of ${ }^{\text {SO }}$ from radiolabeled molecules and uptake by the skeleton with resultant bone marrow toxicity. We attempted to evaluate the importance of this factor by a comparison of the radiation dose to the marrow when chelated by either of two high afinity chelators, MX-DTPA or BAD.

Quanttative autoradlography revealed substantlally greater uptake of ${ }^{\circ} Y$ in the skeloton when MX-DTPA was used as the chelator. These observations suggested that oy escape to bone was a significant factor in the maximum tolerated dise of radiolabeled targeted molecule that can be used in therapeutic trials. Meanwhile, results of ismor imaging with autoradiography confirmed a uniform radiation dose distribution of ${ }^{20}$ in mico for both cholators (140).

\section{CUNRCAL STUDIES}

The objective of quantitative imaging is to provide information on molecular behavior in patients that is analogous to that provided by biodistribution studies in mice. The amount of radionuclide in a specilic sito can be estimated by relating the counts detected in a defined region of interest to the total radionuclide content. The rellability of evaluations using quantitative imsging have been further investigated by correlating image quantitation with counts of biopey samples and dertving $\mathbf{S}$ factors for tumor and organ radiation dose calculation. Inages of patients who had received intravenous targeted molecules labeled with 111 In, "Cu or ${ }^{191}$ I were obtained and quanttations performed by previousty described mothods $(141,142)$. Uaing the techniques described, wo wore able to study dynamic molecular blodistributions and evaluate eficacy and toxicity of various molecular constructs and radionuclides.

Image Quentitition verses Count From Biopoy Samples. To further assess the accuracy of image quantitation in-vivo, we have compared tumor quanttation results from imaging mothods with blopsy counting methods. A correlation was found between the concentration 
of radionuclide observed by counting tumor biopsy samples and that observed by quantitathe imaging (Figure 10).

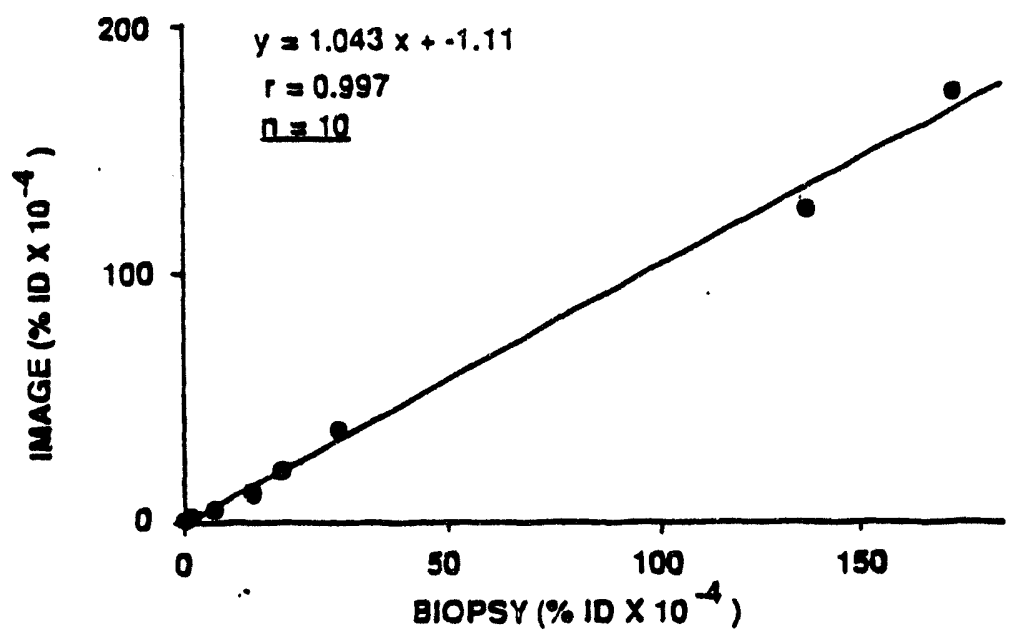

Figro 10.

Corrolation of tumor concentration of 1-131 Lym-1 dotermined by counting blopoy sample and imaging pattent.

S Factors For Radiation Dose Calculation. Studles have been carried out to identify possible sources of error in radiation dose estimation apart from activity quantitation. The influence of remaining body activity on the calculated radiation absorbed doses dellvered to various organs or tumor aites in the body has been investigated for patients receiving diagnostic and therapy doses of ${ }^{131}$ / labeled Lym-1 considering the liver as both the target and the source. Good agreement was found using the corrected cumulated activity and the corrected $S$ factor methods. Doses were overestimated by up to $20 \%$ for the liver using the straightforward MIRD approach. This correction factor was small for typical tumor sites of less than $100 \mathrm{ml}$ with uptake of less than $1 \%$ of the administered dose. The remaining body activity correction factor can be elegantly calculated for any site in the body from a whole body image and a static image of a specific site.

Currently available MIRD tables hove been commonly used for calculation of radiation dosimetry for tumors up to 100 grams (143). However, it is not uncommon to find tumor mase greater then 100 grame in clinical studies. Methods need to be developed to derive $S$ factors for larger tumors. Wo have ovaluated simple interpolation methods to estimate $S$ factors for various tumors by interpolation of $S$ factors of normal organs in the MIRD table. Because of the relattvely small amounts of contribution from penetrating radiations (for ${ }^{\circ 7} \mathrm{Cu}$ and ${ }^{131} \mathrm{D}$, simple interpolation of $\mathrm{S}$ factors is possible with reasonable accuracy. The quanttlative difference between tumor $S$ factors derived from the interpolation method and those derived by the method.of Elett \& Humes (143) is less than $7 \%$. These results encouraged us to extend this work in tuture studies for dertving $\mathbf{S}$ factors for organs in individual patients using simple interpolation methods.

- Cu maging Studies For Lymphoma Cancer. Imaging is used to ovaluate novel radiolabeled targoted molecules in the ultimate biologic system, l.e. pationts. Whilo ${ }^{131} /$ is a practical radionuclide, it is not ideal for targeted molecular therapy because of dehalogenation and subetantlal imaging and radiation safoty problems secondary to multiple onergetic photons. 
"Cu has been actvocated for bageted molecular therapy because of th superior phyalcal characturtstios and observattons that its retention in tumors when conjugated to targoted molecules was longer than that of the corresponding radioiodinated targoted molecule leading to an increased radiation absorbed dose to the tumor. Quantitative imaging was used to explors the use of ${ }^{7} \mathrm{Cu}$ as thorapeutic radionuclides for targeted molecular therapy.

The efficiencies of our scintillation cameras were about four times greater for ${ }^{\circ} \mathrm{Cu}$ than for ${ }^{131}$, desplte the lesser abundance of " $\mathrm{Cu}$ photons. This relates to the fact that the photons of "Cu are "inc-llke in energy and more efficient for a scintillation camera than the more energottc photons of ${ }^{131} \%$. For the same amount of radloactivity and number of counts, supert images were obtained four times faster after injection of "ir CU-BAT-Lym-1 than attor injection of ${ }^{39} 1 \mathrm{Lym}-1$. The quality and resolution of the ${ }^{\circ} \mathrm{Cu}$ images were supertor to those obtained with ${ }^{131}$ I (Figure 11).

Figure 11.
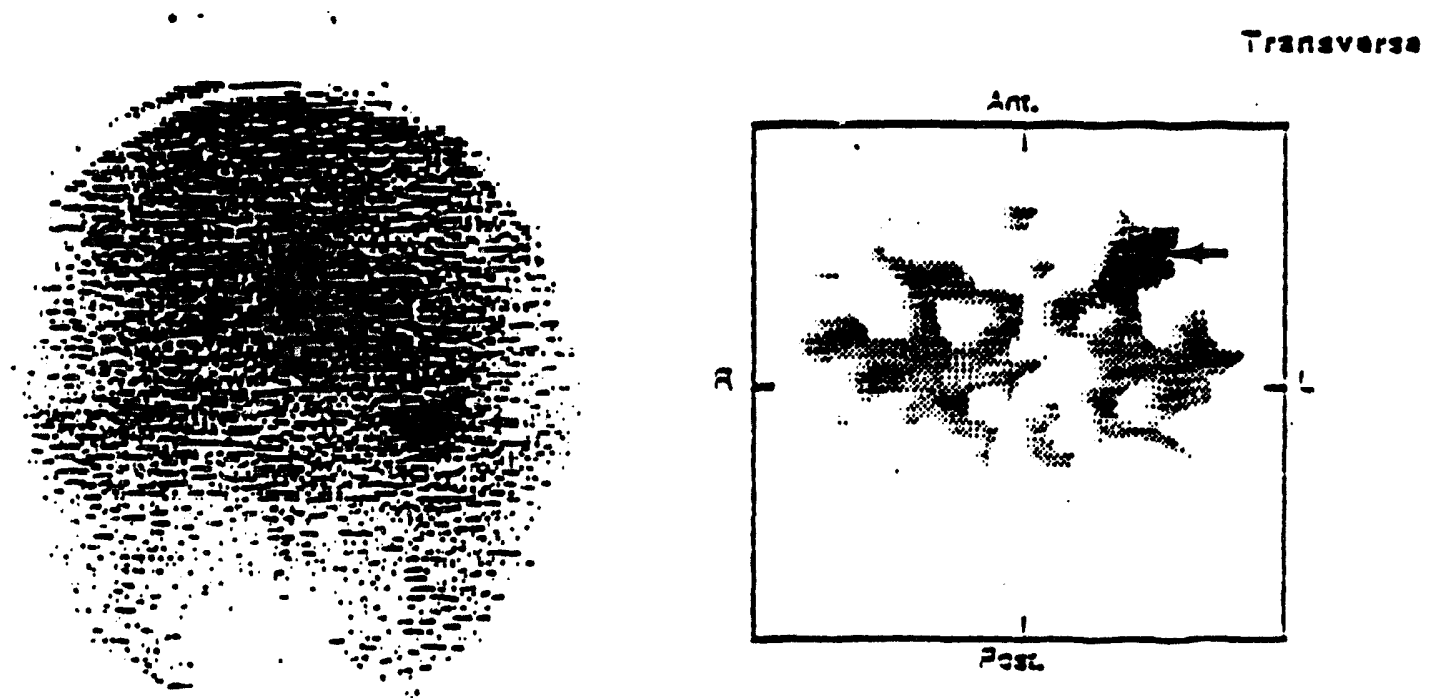

Rotention of ${ }^{77} \mathrm{Cu}$ by the iver was longer than that of ${ }^{131} /$ leading to a modestly greater radiation absorbed dose to the Ilver which is not a doso limiting organ (Table 5).

TABLE 5.

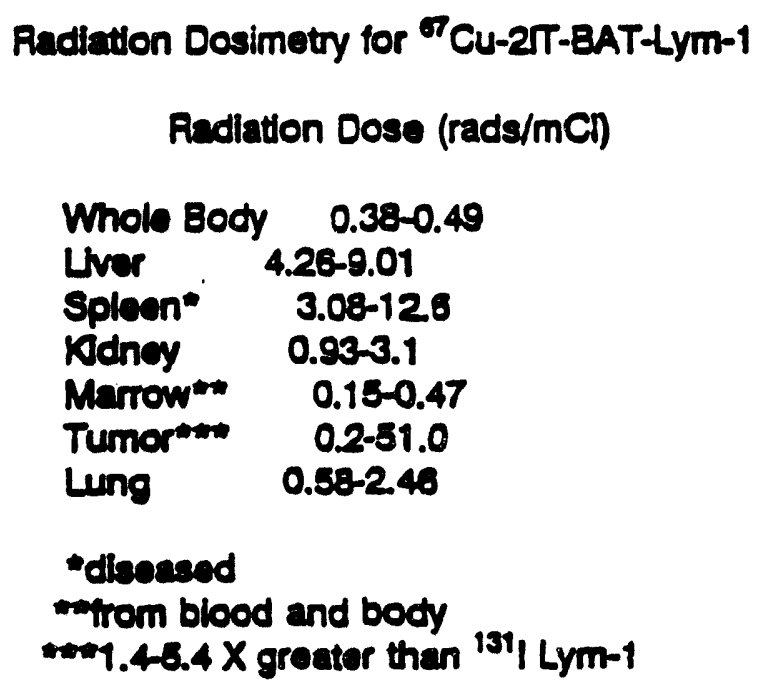

Page 1 1?.0 
Targoted molecular imaging allowed us to compare the dosimotry for ${ }^{7}$ Cu-2rT-BAT-Lym-1 with that for ${ }^{131} / \mathrm{Lym}-1$. In all instances, the radiation absorbed dose to the tumors wes 1.45 .4 tmes greater for "Cu than for ${ }^{131}$ I because the ${ }^{77} \mathrm{Cu}$ was retained in the tumors much longer than was F31. Pationts that recelved ${ }^{87}$ CU-2T-BAT-Lym-1 had significant decreases in the sizo of their tumors atter administration of the antibody.

111 In MoNb imeging Studies For Bread Cencer to Predict of MoNb Therapy. SOY is another radionuelide bound to novel molecular constructs that has been Investigated by imaging. Dy has attracted considerable attention for targeted molecular therapy because its physical properties decrease radiation safety concerns and avoid the requirement for hospitalization. Its long range bota emission reduces the problem of tumor penotration. Furthermore, radiomotal immunoconjugates, such as those of ${ }^{\circ} Y$, have longer residence times in malignant tissues than equivalent lodinated immunoconjugates, albolt, this is often true for normal tissues as well. These considerations contributed to development of molecular probes attached to ${ }^{\text {oy }}$ and the use of these "Y molecular agents in clinical trials of targoted molecular therapy, such as BrE-3, an antibreast cancer MoAb formulated with MX-DTPA. Because Coy lacks gamma emisaions for imaging studies, ${ }^{111}$ in labeled antbody has been co-administered since its chemical behavior is analogous to that of ${ }^{\text {POY. }}$.

Patlent imaging studies demonstrated excellent tumor uptake for this and-breast cancer molecular probe (Figure 12).

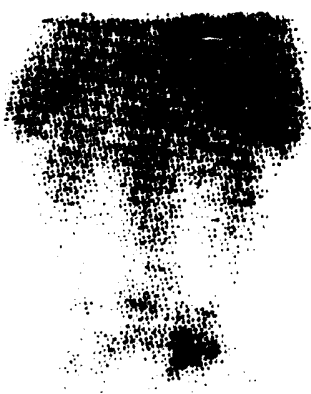

Fioure 12

The advantage of ${ }^{\text {Doy }}$ over ${ }^{131}$ / can be easily illustrated, for example, as we compare tumor radiation doee for a MoAb targoted to broast cancer, ChL8, laboled with oY and ${ }^{131}$. Uptake of ${ }^{131}$ 1-ChL6 observed in tumors of pattents in clinical trials has ranged from 0.1 to $0.001 \% \mathrm{lO} / \mathrm{gm}$. Using this range of uptake for ${ }^{131}$, ChL6 and for ${ }^{20}$ DOTA ChLs and the biological data observed for human adenocarcinoma tumors in nude mice for ${ }^{131}$ I ChL6 and for ${ }^{\text {SO }}$ ChL6, the following table was generated using conventional mothods and confirms the enhanced radiation to the tumor that can be expected when oy is used for therapy (Table 6). 
DE FCosengacoexs

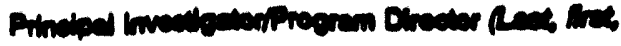

Dewnoo, sery d

TABLE Q

RAD DOSE TO TUMOR (19r fon per mCA

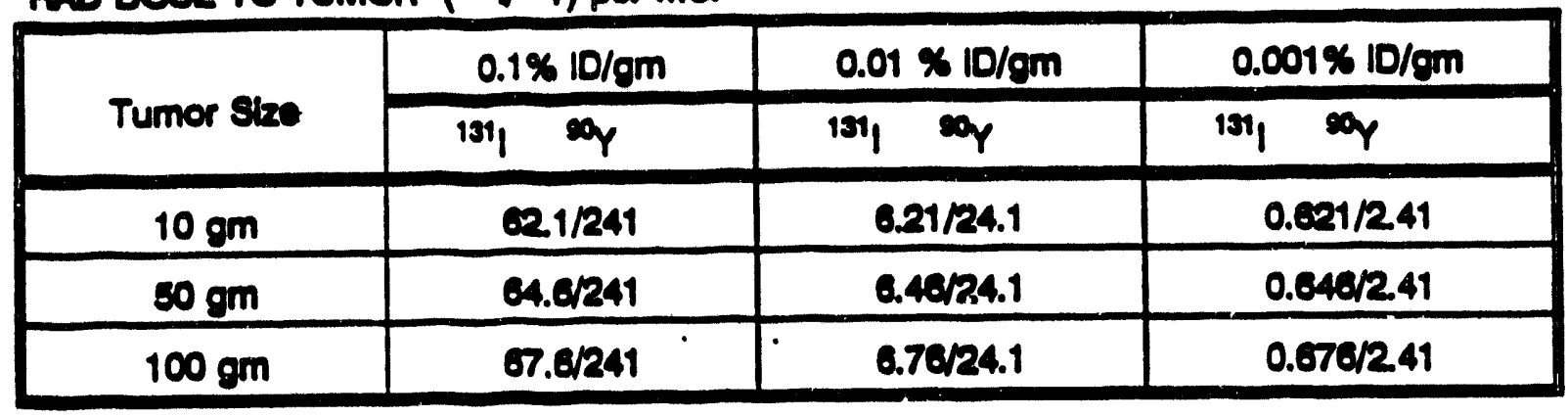

Paco 1?.? 

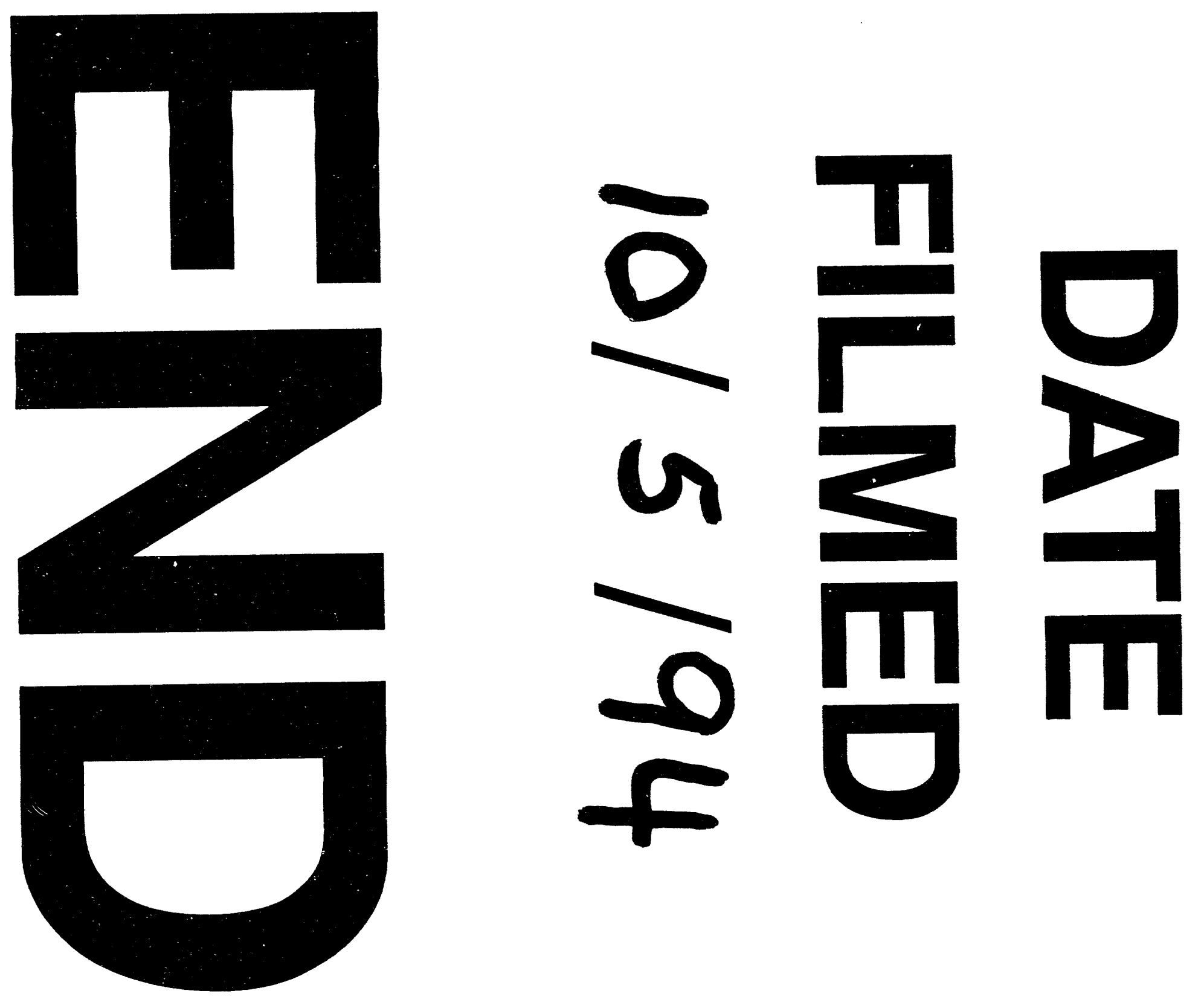


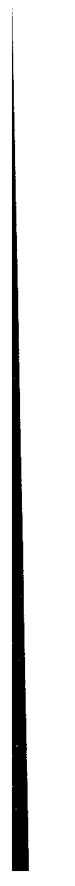

